Article

\title{
Wave-to-Wire Model Development and Validation for Two OWC Type Wave Energy Converters
}

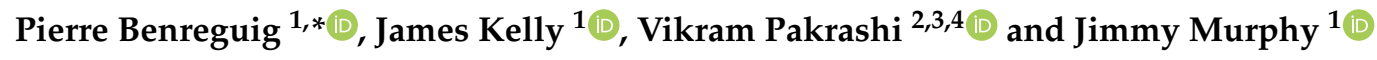 \\ 1 MaREI Centre, Beaufort Building, University College Cork, Haubowline Road, P43C573 Ringaskiddy, \\ Co. Cork, Ireland; James.Kelly@ucc.ie (J.K.); Jimmy.Murphy@ucc.ie (J.M.) \\ 2 Dynamical Systems and Risk Laboratory, School of Mechanical and Materials Engineering, University College \\ Dublin, D04V1W8 Dublin, Ireland; Vikram.Pakrashi@ucd.ie \\ 3 SFI MaREI Centre, University College Dublin, D04V1W8 Dublin, Ireland \\ 4 The Energy Institute, University College Dublin, D04V1W8 Dublin, Ireland \\ * Correspondence: pierre.benreguig@ucc.ie
}

Received: 28 August 2019; Accepted: 14 October 2019; Published: 18 October 2019

check for updates

\begin{abstract}
The Tupperwave device is a closed-circuit oscillating water column (OWC) wave energy converter that uses non-return valves and two large fixed-volume accumulator chambers to create a smooth unidirectional air flow, harnessed by a unidirectional turbine. In this paper, the relevance of the Tupperwave concept against the conventional OWC concept, that uses a self-rectifying turbine, is investigated. For this purpose, wave-to-wire numerical models of the Tupperwave device and a corresponding conventional OWC device are developed and validated against experimental tests. Both devices have the same floating spar buoy structure and a similar turbine technology. The models include wave-structure hydrodynamic interaction, air turbines and generators, along with their control laws in order to encompass all power conversion stages from wave to electrical power. Hardware-in-the-loop is used to physically emulate the last power conversion stage from mechanic to electrical power and hence validate the control law and the generator numerical model. The dimensioning methodology for turbines and generators for power optimisation is explained. Eventually, the validated wave-to-wire numerical models of the conventional OWC and the Tupperwave device are used to assess and compare the performances of these two OWC type wave energy device concepts in the same wave climate. The benefits of pneumatic power smoothing by the Tupperwave device are discussed and the required efficiency of the non-return valves is investigated.
\end{abstract}

Keywords: wave energy; oscillating water column; air turbine; valves; wave-to-wire model

\section{Introduction}

Harnessing wave energy to produce electrical energy in an economically sustainable way requires the development of efficient and reliable wave energy converters. Despite significant research and development, the concepts for converting wave energy into electricity still have not converged to any favoured solution [1]. The oscillating water column (OWC) concept is among the most promising types of devices due to its simplicity and robustness and is therefore the most extensively studied [2]. An OWC consists of a partially submerged fixed or floating hollow structure, open to the sea below the water surface, that traps air between the inner free-surface and the top of the structure; under the wave excitation, the internal water column oscillates in the structure and alternately compresses and decompresses the trapped air which is forced in and out of the structure through a turbine coupled to a generator. 
In the most common form of OWC, the compression and decompression of the air in the chamber directly creates a bidirectional flow across a self-rectifying turbine opened to the atmosphere. Such a turbine can harness both in-coming and out-coming flows. Their rotational direction remains unchanged regardless of the direction of the air flow. Several types of such special turbines have been developed: Wells and impulse turbines are the two main types of self-rectifying turbines [2]. Their maximum total-to-static efficiency in constant flow condition varies between $30 \%$ and $72 \%$ depending on their level of complexity and cost [3]. To date, the biradial and twin-rotor turbines are the best performing self-rectifying turbines and reach, respectively, about $79 \%$ and $74 \%$ efficiency in steady flow conditions [4,5]. In real ocean conditions, the flow across the turbine is, however, highly fluctuant and stops at every half-wave period to change direction. In these conditions, the average efficiency of self-rectifying turbines drops by 5 to $10 \%$ [3].

Other forms of OWC devices use non-return valves to rectify the flow across a unidirectional turbine. The incentive is that unidirectional turbines are more efficient than self-rectifying turbines with efficiencies higher than $85 \%$ [6,7]. Various OWC devices using a unidirectional turbine have been studied and different methods for rectifying the air flow have been considered: The Masuda's navigation buoy [2], the Kaimei [8], the Leancon [9] and the vented OWC from wave swell energy [10] all use a different air flow rectification method. Rectifying valves, however, induce pneumatic power losses [11] and can also be unpractical at full scale [8].

The Tupperwave concept, described in [12], is equipped with two non-return valves, two large air chambers that act as accumulators and a unidirectional turbine. The vertical motion of the internal water surface (IWS) alternatively compresses the air into the high-pressure chamber (HP chamber) and decompresses the air in the low-pressure chamber (LP chamber). This creates a differential of pressure between the HP and LP chambers which are connected via the unidirectional turbine. The air flows in a closed-circuit in the device.

In order to study the relevance of the Tupperwave principle against the conventional OWC principle, two devices using each principle and the same floating spar buoy structure are compared in this article. The chosen floating structure is an axisymmetric spar buoy which suits both working principles. The volume of the Tupperwave HP and LP chambers is maximized according to an optimization study [13] and hence the whole buoyancy volume is used. Each chamber is $950 \mathrm{~m}^{3}$. The electrical power performance of each device in terms of electrical energy production and power quality are to be assessed and compared. For this purpose, complete wave-to-wire numerical models of the two devices presented in Figure 1 are required.

The power conversion chain of an OWC type device is split in four main stages. Part of the wave power $P_{w}$ reaching the device is absorbed by the floating device. The absorbed power $P_{a b s}$ is the power applied by IWS on the air contained in the OWC chamber. It is then converted into pneumatic power $P_{\text {avail }}$ available across the turbine. The pneumatic power is converted into mechanical power $P_{m}$ by the turbine and further converted into electrical power $P_{e}$ by the generator. Accurate wave-to-wire modelling requires the modelling of each power conversion stage and a validation against physical results. Such modelling and validation has already been achieved for OWC devices. This was done, for example, in [14], where the model is verified using experimental data from open sea device deployment. The model can then be used to test control strategies in specific conditions. However, if the device is at an earlier development stage, as is the case in this paper, no large scale prototype data are yet available. The wave-to-wire model validation therefore has to be done step-by-step across the power conversion stages using scaled lab tests. The power performances of the device can then be predicted using the validated model before the building and deployment of a large scale prototype.

In [15], numerical models from wave power to pneumatic power of the Tupperwave device and corresponding conventional OWC were developed and the results were validated against physical tank testing at $1 / 24$ th scale. The results also demonstrated the capacity of the Tupperwave concept to produce a smoother pneumatic power made available to the turbine. In this paper, the models from [15] are extended to build complete wave-to-wire models which are validated step-by-step as illustrated 
in Figure 2. The models are then used to compare the power performance of both devices and conclude on the relevance of the innovative Tupperwave concept.

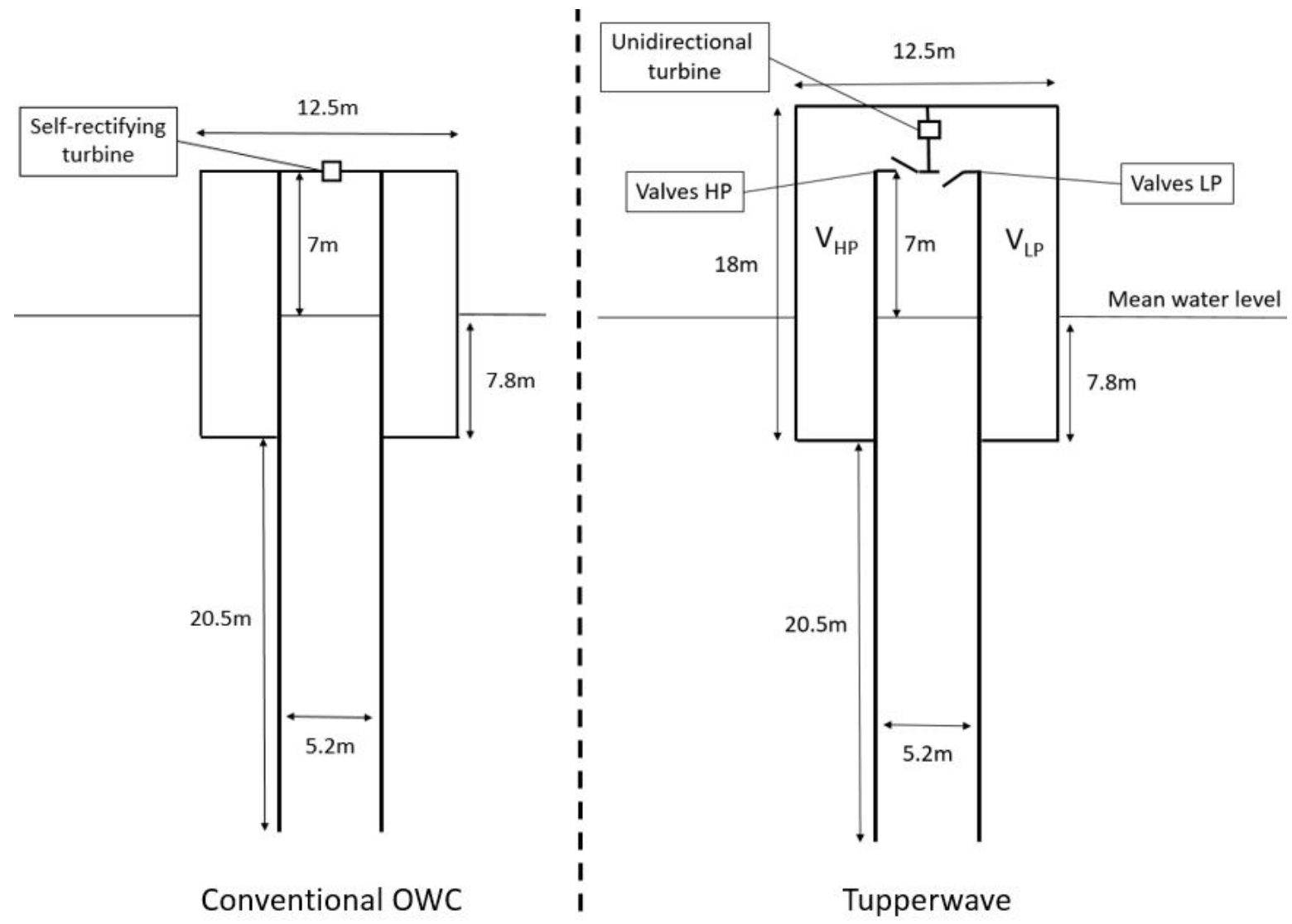

Figure 1. Two-dimensional schematic of the full scale conventional oscillating water column (OWC) and Tupperwave devices.

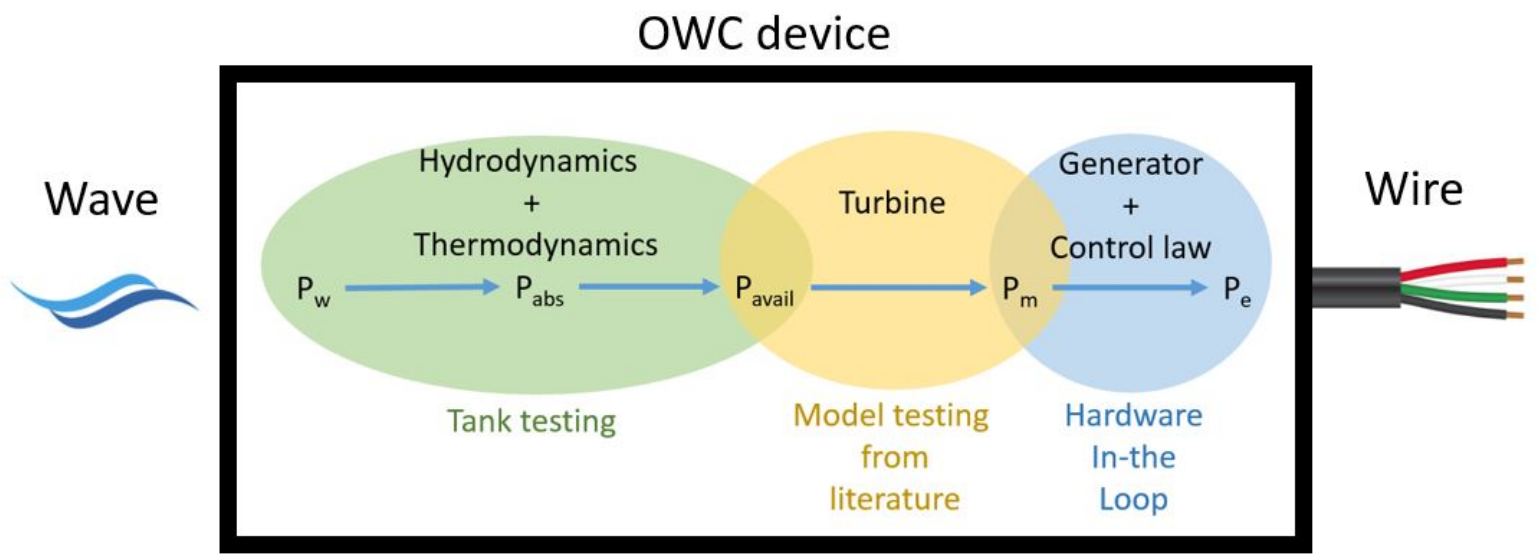

Figure 2. Schematic of power conversion chain of OWC device from wave to wire and step-by-step validation methods achieved in $[6,15]$ and the present paper.

In Section 2 of this paper, the rest of the power conversion chain is considered and added to the existing models by the addition of a turbine and generator model to obtain the complete wave-to-wire models of the two devices. Section 3 explains the dimensioning methodology used on the turbine-generator systems for the devices' power performance optimisation in the wave climate of the EMEC test site located in Orkney, Scotland. Hardware-in-the-loop experiments were carried 
out to provide physical validation for the last power conversion stage and are described in Section 4 . Eventually, the complete wave-to-wire models are used in Section 5 to assess and compare the power performances of the Tupperwave device and conventional OWC equipped with state of the art turbines in the EMEC wave climate. The impacts of the pneumatic power smoothing capacity of the Tupperwave working principle are identified.

\section{Wave-to-Wire Models}

The wave-to-wire models are based on several considerations. Hydrodynamic and thermodynamic equations were used in [15] for the development of wave-to-pneumatic power models and are first summarized for the two full scale devices. The rest of the power conversion chain is then described. State-of-the-art turbines are chosen and modelled using physical testing results from the literature. Finally the generator model and its control are presented.

\subsection{Hydrodynamics}

The Tupperwave device and the conventional OWC use the same floating spar structure. Therefore, the hydrodynamic wave-structure interactions for both devices can be described by the same set of equations within the linear wave theory. The structure and the water column are considered as two rigid bodies moving in heave only in the waves relatively to each other. The coupled heave motions of the two bodies (noted with indices 1 and 2) can be written in time-domain as $[15,16]$ :

$$
\left\{\begin{array}{c}
{\left[m_{1}+A_{11}(\infty)\right] \ddot{x}_{1}(t)+\int_{0}^{t} K_{11}(t-\tau) \dot{x}_{1}(t) d \tau+A_{12}(\infty) \ddot{x}_{2}(t)} \\
\quad+\int_{0}^{t} K_{12}(t-\tau) \dot{x}_{2}(t) d \tau+c_{1} x_{1}(t)=f_{1}(t)+f_{p}(t)+f_{d 1}(t) \\
A_{21}(\infty) \ddot{x}_{1}(t)+\int_{0}^{t} K_{21}(t-\tau) \dot{x}_{1}(t) d \tau+\left[m_{2}+A_{22}(\infty)\right] \ddot{x}_{2}(t) \\
\quad+\int_{0}^{t} K_{22}(t-\tau) \dot{x}_{2}(t) d \tau+c_{2} x_{2}(t)=f_{2}(t)-f_{p}(t)+f_{d 2}(t)
\end{array}\right.
$$

where $m_{i}$ are the bodies' masses; $A_{i j}(\infty)$ are the bodies' heave motion added masses at infinite frequency; $c_{i}$ are the restoring force coefficients; $K_{i j}$ are the impulse response functions for heave motions and their interactions; $f_{i}$ are the wave excitation forces. $f_{p}$ is the reciprocating pressure force acting on both bodies and is calculated as: $f_{p}=S p_{\text {owc }}(t)$ where $S$ is the internal water free surface in the water column and $p_{\text {owc }}$ is the excess pressure relatively to atmospheric pressure built in the OWC chamber. The viscous drag forces $f_{d 1}$ and $f_{d 2}$ are calculated as $f_{d i}=-C_{d i}\left|\dot{x}_{i}(t)\right| \dot{x}_{i}(t)$ where $C_{d i}$ is the equivalent drag coefficient. This force includes the viscous drag effects and all non-linear viscous effects [17]. The equivalent drag coefficients at full scale are unknown. The values of $C_{d 1}=150 \mathrm{~N} \cdot \mathrm{s}^{2} \cdot \mathrm{m}^{-2}$ and $C_{d 2}=40 \mathrm{~N} \cdot \mathrm{s}^{2} \cdot \mathrm{m}^{-2}$ were established using the experimental results from the tank testing at $1 / 24$ th scale [15]. It is, however, to be noted that possible differences on these coefficients between model scale and full scale may arise from different flow characteristics between the two scales. The scaled-up coefficients provide reference values that were used for the numerical models at full scale.

\subsection{Thermodynamics}

The general thermodynamic differential equation relating the excess pressure $p$ and volume $V$ of air considered as a perfect gas in a chamber during isentropic transformations was derived in [15]:

$$
\dot{p}=\frac{\gamma p_{\text {atm }}}{\rho_{\text {atm }} V}\left(w_{\text {in }}-w_{\text {out }}-\rho \dot{V}\right)
$$

where $p_{\text {atm }}$ and $\rho_{\text {atm }}$ are the pressure and air density in atmospheric conditions; $w_{\text {in }}$ and $w_{\text {out }}$ are the mass flow rates of air flowing, respectively, in and out of the system. 
If the system is considered adiabatic and the transformations slow enough to be reversible, the isentropic density-pressure relation is applicable:

$$
\rho=\rho_{a t m}\left(1+\frac{p}{p_{\text {atm }}}\right)^{\frac{1}{\gamma}}
$$

where $\gamma$ is the isentropic expansion factor.

If the excess pressure $p$ remains small compared to the atmospheric pressure $p_{a t m}$, Equation (3) can be linearised:

$$
\rho=\rho_{a t m}\left(1+\frac{p}{\gamma p_{a t m}}\right)
$$

In [18], the linearised isentropic assumption was shown to provide a satisfactory results for the modelling of conventional OWCs except possibly under very rough sea conditions. Hence, the transformations happening in a conventional OWC are commonly modelled in the literature using Equation (4). In the present work, the maximum pressures reached in the extreme sea states tested were in the order of $3 \times 10^{4} \mathrm{~Pa}$. In those conditions, the error introduced by the linearisation of the isentropic relationship between density and pressure does not exceed $0.7 \%$. Thus, for simplicity, Equation (4) is also used in this work.

At full scale, the turbine and the generator need to be protected from possible overloading happening in high energy sea-states. Bypass valves are commonly used as security system in OWC devices for this purpose [18]. The valve is normally closed and located in parallel to the turbine. When it opens, the flow splits between the turbine and the bypass valve, reducing the flow through the turbine and alleviate the load on this latter. The control of the bypass valve is described in Section 2.5.

Figure 3 displays a schematic of the OWC thermodynamic system. The value of mass flow rate $w_{t}$ and $w_{\text {bypass }}$ crossing the turbine and the bypass valves are considered positive whatever the flow direction. Equation (2) applied on the OWC chamber becomes:

$$
\dot{p}_{o w c}=\left\{\begin{array}{lll}
\frac{\gamma p_{a t m}}{\rho_{a t m} V_{o w c}}\left(-\left(w_{t}+w_{\text {bypass }}\right)-\rho_{o w c} \dot{V}_{o w c}\right) & \text { for } & p_{o w c}>0 \\
\frac{\gamma p_{a t m}}{\rho_{a t m} V_{o w c}}\left(+\left(w_{t}+w_{\text {bypass }}\right)-\rho_{o w c} \dot{V}_{o w c}\right) & \text { for } & p_{o w c}<0
\end{array}\right.
$$

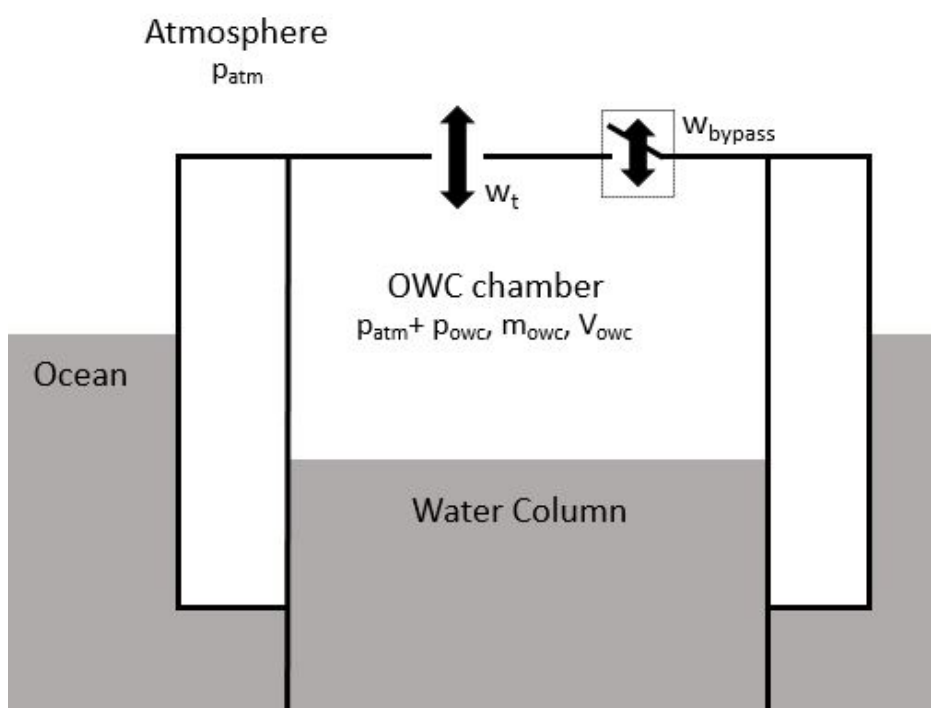

Figure 3. Conventional OWC schematic with thermodynamic variables. 
Figure 4 displays a schematic of the three chambers of the Tupperwave device which constitute three interconnected thermodynamic systems. Unlike in the conventional OWC, in which the air is partly renovated during the inhalation part of the cycle, the air in the Tupperwave device is exchanged between the chambers in closed-circuit with no exchange with the atmosphere. This brings into question the possible air temperature increase in the device due to energy dissipation by viscous effects across the turbine and the valves. The study of such irreversible processes is not in the scope of this research and it is assumed that the heat transfer through the device walls into the environment is sufficient to prevent the temperature in the device to rise significantly above atmospheric conditions. Moreover, the pressure conditions in the Tupperwave device being of similar order to the ones in the conventional OWC, the linearised isentropic assumption is also adopted for the Tupperwave device and Equation (2) is directly applied to the three chambers:

$$
\left\{\begin{array}{l}
\dot{p}_{o w c}=\frac{\gamma p_{a t m}}{\rho_{a t m} V_{o w c}}\left(w_{v l}-w_{v h}-\rho_{\text {owc }} \dot{V}_{\text {owc }}\right) \\
\dot{p}_{h p}=\frac{\gamma p_{a t m}}{\rho_{a t m} V_{h p}}\left(w_{v h}-\left(w_{t}+w_{\text {bypass }}\right)\right) \\
\dot{p}_{l p}=\frac{\gamma p_{a t m}}{\rho_{\text {atm }} V_{l p}}\left(\left(w_{t}+w_{\text {bypass }}\right)-w_{v l}\right)
\end{array}\right.
$$

where $w_{t}, w_{\text {bypass }}, w_{v h}$ and $w_{v l}$ are the air mass flow rates across the turbine, the HP valve and the LP valve. The expression of these flows as functions of the pressure are established using the turbine and valve models.

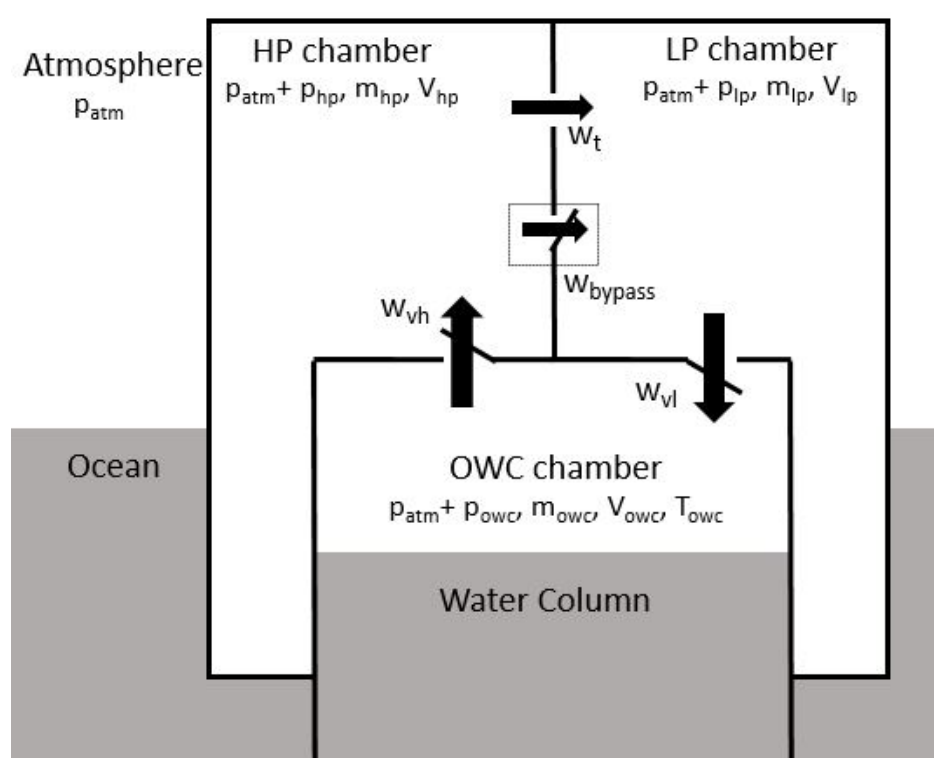

Figure 4. Tupperwave device schematic with thermodynamic variables.

\subsection{Tupperwave Non-Return Valves}

The valves are a key components in the Tupperwave device efficiency because they cause pneumatic power losses. The effective area of the valves and the opening pressure are the key parameters for the device efficiency [11]. Passive valves do not require to be electrically activated and are therefore very easy to implement. The use of passive valves in the full-scale Tupperwave device is justified to reduce the device mechanical and electrical complexity and hence to reduce its price. In this paper, the same passive valve model as in [15] is used. The valves only allow air flow in one direction when the pressure head $\Delta p_{v}=p_{\text {in }}-p_{\text {out }}$ is larger than their opening pressure $p_{0}$. In high energy sea states, the Mach number of the flow across the valves rises above 0.3. Hence, the flow 
is considered as compressible and a steady-state subsonic compressible flow model is adopted to calculate the air mass flow rates across the valves [19]:

$$
w_{v, \text { in } \rightarrow \text { out }}=\left\{\begin{array}{ccc}
0 & \text { if } & p_{\text {in }}-p_{\text {out }}<p_{0} \\
\alpha A_{v} \sqrt{\frac{2 \gamma}{\gamma-1} \rho_{\text {in }}\left(p_{\text {in }}-p_{0}\right)\left(r^{\frac{2}{\gamma}}-r^{\frac{\gamma+1}{\gamma}}\right)} & \text { if } & p_{\text {in }}-p_{\text {out }}>p_{0}
\end{array}\right.
$$

where $r=\frac{p_{\text {out }}}{p_{\text {in }}-p_{0}}$ is the pressure ratio over the valve when open; $\alpha A_{v}$ is the effective opening area of the valves when fully opened [18]. To maximise the efficiency of the valves, the effective area should be maximised while the opening pressure should be minimised. No valves were designed and studied for the full scale device. Moreover, hardly any information on non-return valves for large OWC devices is available in the literature. Therefore, it is hard to know what effective area and opening pressure are practically achievable at full scale. During physical model testing carried out at model scale in $[11,15]$, the valves caused very important pneumatic power losses, dissipating up to $60 \%$ of the absorbed wave power. They operated at best with a effective area of $0.286 \mathrm{~m}^{2}$ at full scale equivalent. The area available for the valve connecting the OWC chamber to the HP chamber (resp. LP chamber) is about $10 \mathrm{~m}^{2}$. With such a large available area, it is very likely that properly designed full scale valves could reach larger effective opening area than $0.286 \mathrm{~m}^{2}=53 \times 53 \mathrm{~cm}$. Nevertheless, this value will be used in the wave-to-wire model as a reference value. Regarding the opening pressure, a pressure differential of 150 Pa between both sides of the valve is equivalent to a force of $43 \mathrm{~N}=4.4 \mathrm{kgf}$ acting on the valve. Considering the small dimensions of the valve, such force should be sufficient to open it. The value of $p_{0}=150 \mathrm{~Pa}$ was therefore chosen as a reasonable pressure value to activate the opening of the valves. The influence of the values of $\alpha A_{v}$ and $p_{0}$ are investigated in Section 5 .

\subsection{Turbine Model}

The conventional OWC and the Tupperwave device are equipped with two different turbines, which will be described in Section 3.1. However, the numerical modelling remains the same for both turbines. The mechanical power $P_{\text {mech }}$ extracted by a turbine from an air flow is a function of its diameter $\mathrm{D}$, its rotational speed $\Omega$, its pressure head $\Delta p_{t}=p_{\text {in }}-p_{\text {out }}$ between inlet and outlet, and of the volumetric air flow rate $q_{t}$ flowing across a turbine. These relationships are usually presented in dimensionless form, assuming incompressible flow and using the dimensionless flow coefficient $\Phi$, dimensionless pressure head $\Psi$ and dimensionless turbine power output $\Pi$ which are defined as [2]:

$$
\Phi=\frac{q_{t}}{\Omega D^{3}} ; \quad \Psi=\frac{\Delta p_{t}}{\rho_{i n} \Omega^{2} D^{2}} ; \quad \Pi=\frac{P_{\text {mech }}}{\rho_{\text {in }} \Omega^{3} D^{5}}
$$

The dimensionless coefficients can be related by the polynomial functions $f_{\Psi}$ and $f_{\Pi}$, established at model scale during laboratory tests:

$$
\Psi=f_{\Psi}(\Phi) ; \quad \Pi=f_{\Pi}(\Phi)
$$

Neglecting the influence of the Reynolds and Mach numbers, the dimensionless turbine representation enables to describe any geometrically similar scaled-up version of the turbine.

From Equations (8) and (9), the mass flow rate crossing the turbine can be expressed as a function of pressure head and its expression can be used in Equations (5) and (6):

$$
w_{t}=\rho_{\text {in }} q_{t}=\rho_{\text {in }} \Omega D^{3} f_{\Psi}^{-1}\left(\frac{p_{\text {in }}-p_{\text {out }}}{\rho_{\text {in }} \Omega^{2} D^{2}}\right)
$$


The total-to-static turbine efficiency $\eta_{t}$ is obtained by the ratio of the mechanical power of the turbine $P_{m}$ and the pneumatic power available to the turbine $P_{\text {avail }}$ :

$$
\eta_{t}=\frac{P_{m}}{P_{\text {avail }}}=\frac{P_{m}}{q_{t} \times \Delta p_{t}}=\frac{\Pi}{\Phi \times \Psi}=f_{\eta}(\Phi)
$$

The turbine reaches a maximum of efficiency for an optimal dimensionless flow coefficient $\Phi_{\text {opt }}$.

\subsection{Generator Model, Bypass Valve and Control Law}

The mechanical power from the turbine is finally converted into electrical power by the generator. Newton's law applied on the generator rotor gives:

$$
I \dot{\Omega}=T_{\text {turb }}-T_{g e n}-T_{\text {wind }}
$$

where $I$ is the inertia of the turbine-generator system; $T_{\text {gen }}$ is the electromagnetic braking torque applied by the generator; $T_{\text {wind }}$ is the aerodynamic friction torque due to windage losses of the twin-rotor turbine (only relevant for the conventional OWC, see Section 3.1); $T_{\text {turb }}$ is the mechanical torque applied by the turbine obtained from Equations (8) and (9) by:

$$
T_{\text {turb }}=\frac{P_{\text {mech }}}{\Omega}=\rho_{h p} \Omega^{2} D^{5} f_{\Pi}(\Phi)
$$

The control of the turbine-generator system is achieved via the generator torque. In this paper, the control strategy implemented is a maximum power point tracking (MPPT) based on optimal torque control. It is sought to optimise the instantaneous turbine efficiency by matching the generator braking torque to the torque expected to be produced by the turbine at maximum efficiency. According to Equation (8), the value of $T_{\text {gen }}$ is obtained by:

$$
T_{\text {gen }}=T_{\text {turb }}\left(\Phi_{\text {opt }}\right)=\frac{P_{m}\left(\Phi_{\text {opt }}\right)}{\Omega}=\rho_{\text {in }} \Omega^{2} D^{5} f_{\Pi}\left(\Phi_{\text {opt }}\right)
$$

We note that with this control law, the generator torque only depends on the rotational speed such that $T_{\text {gen }}=a \Omega^{2}$ with $a=\rho_{i n} D^{5} f_{\Pi}\left(\Phi_{\text {opt }}\right)$. It is a fast, robust, simple and well-established control law to implement since it does not require any additional sensor [20]. Moreover, no power is required from the grid and energy only flows in one direction. For example, a nearly identical strategy to the MPPT control was used as a base case control strategy for comparing more complex control algorithms during sea trials of a OWC device in [21].

Care must, however, be taken so that the generator rotational speed remains within its operational range $\left[\Omega_{\min } ; \Omega_{\max }\right]$. In low energy sea states, the generator braking torque is dropped to zero for $\Omega<\Omega_{\text {min }}$ and no electrical power is produced. In high energy sea states, the generator is at risk to be over spun. The generator and the power electronics are limited by their rating power, the maximum braking torque $T_{\text {gen, } \max }=P_{\text {rated }} / \Omega_{\max }$ is reached when $\Omega>\Omega_{\max }$. The normally closed bypass valve, located in parallel to the turbine, is electrically activated and opens fully when the generator is overloaded to reduce the flow across the turbine until the condition $\Omega<\Omega_{\max }$ is satisfied again. This security system dissipates the excess energy and prevents the over spinning of the generator. The same valve model as in Equation (7) is used to calculate the mass flow rate $w_{v, \text { bypass }}$ across the bypass valve. For quick relief of the turbine pressure head, the opening area of the bypass valve $\alpha A_{v, \text { bypass }}$ was chosen of $0.15 \mathrm{~m}^{2}$.

Then, the electromagnetic power $P_{e m}=\Omega T_{g e n}$ is converted into electricity by the generator with the efficiency $\eta_{g e n}$. The efficiency of a generator is largely dependant on its load $\Lambda=\frac{P_{e m}}{P_{\text {rated }}}$ where $P_{\text {rated }}$ is the generator rated power. The efficiency drops very sharply for partial loads. $\eta_{g e n}$ was taken 
from [22] and is displayed in Figure 5 as a function of the load. The dimensioning of the generator is discussed in Section 3.

Finally, the electrical power produced by the generator is conditioned by power electronics before being delivered to the grid. The influence of the conditioning stage on the device efficiency is neglected here. As shown in [23], this assumption is reasonable in applications such as control parameters optimisation and power production assessment. The electrical power produced by the generator is therefore simply calculated as:

$$
P_{\text {elec }}=\eta_{g e n} P_{e m}
$$

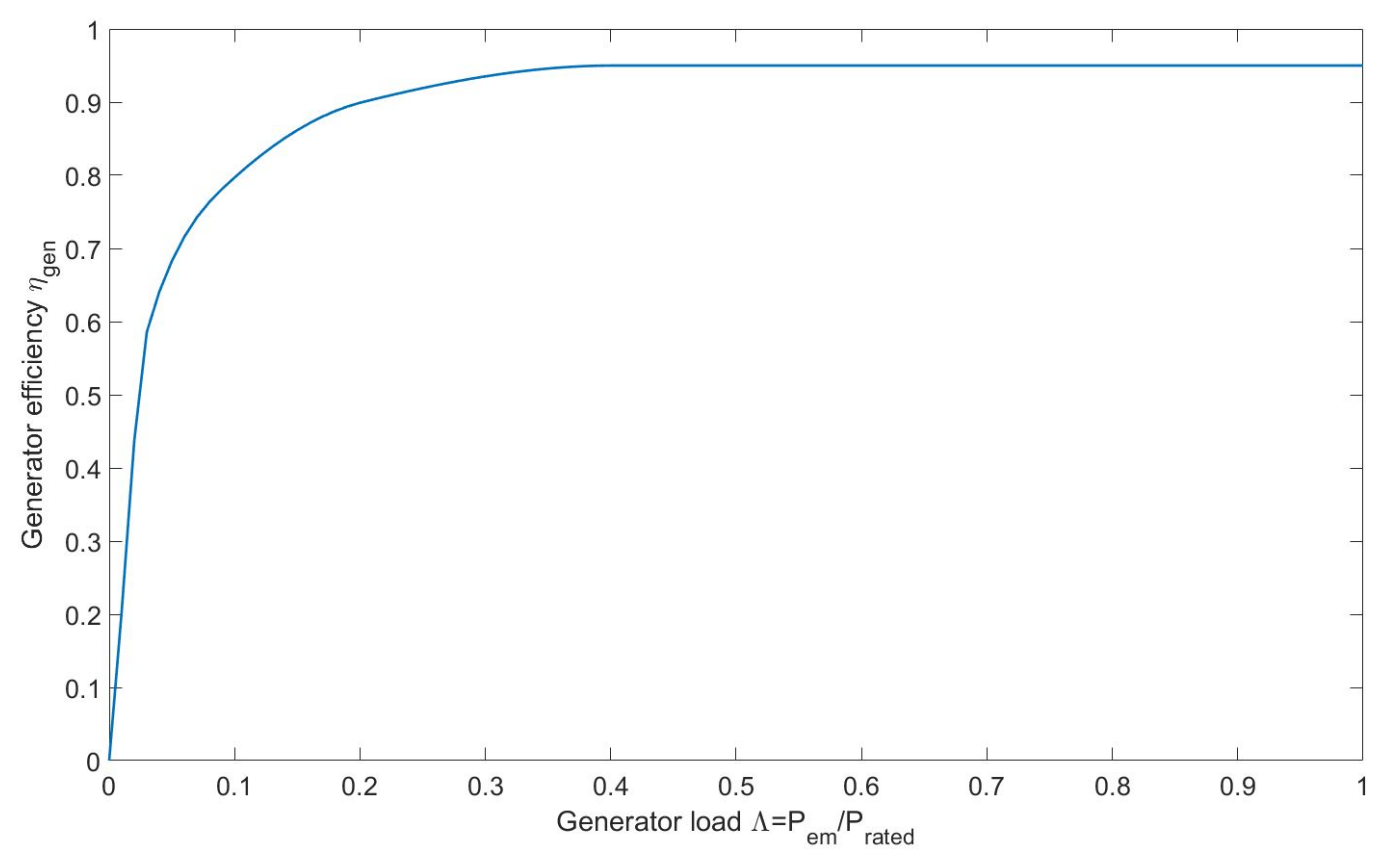

Figure 5. Generator efficiency curve as a function of the load based on [22].

\subsection{Numerical Integration}

Equations (1), (6) and (12) form the system of differential equations governing the behaviour of the Tupperwave device. The conventional OWC is governed by Equations (1), (5) and (12). Each of the four convolution integrals in Equation (1) are approximated using the Prony's decomposition method at order four. Details of the method can be found in [24,25]. The numerical integration of these equations is achieved using the ordinary differential equation solver ode 45 from the mathematical software MATLAB [26].

\section{Turbine-Generator Systems Dimensioning}

\subsection{Turbines}

The objective of the paper being to assess and compare the power performances of the Tupperwave device against a conventional OWC, both devices are equipped with the state-of-the-art turbines.

The twin-rotor turbine, displayed in Figure $6 \mathrm{a}$, is among the most efficient self-rectifying turbines [3]. It uses the idea that a bidirectional flow can be harnessed by two conventional air turbines in parallel: It consists on a pair of conventional radial-inflow rotors mounted on the same shaft in opposite direction, complemented by the corresponding guide vane rows and by a two-position cylindrical valve which, according to the flow direction, orientates the flow through one rotor or the other [27]. At all times, one rotor is driven by the air flow, while the other spins in no flow. The latter creates windage losses due to aerodynamic drag. Due to its symmetry, half of the turbine was built at model scale in [5] in order to assess its performance experimentally (Figure 6b). The resulting 
unidirectional single-rotor radial inflow unidirectional turbine was tested and the polynomial functions $f_{\Psi}$ and $f_{\Pi}$ relating the dimensionless coefficients were established. The experimental assessment of the windage losses allowed the establishment of the twin-rotor turbine dimensionless coefficients.

In this paper, the conventional OWC and the Tupperwave device are, respectively, equipped with the twin-rotor turbine and the corresponding single-rotor unidirectional turbine. Both turbines are therefore very similar and based on the same aerodynamic design. The unidirectional turbine is, however, less mechanically complex with no need for the fast-acting and electrically activated two-position valve. Moreover, due to the windage losses, the twin-rotor turbine is less efficient than the unidirectional turbine: It reaches $72.7 \%$ while the unidirectional turbine reaches $83.9 \%$. Their total-to-static efficiencies in constant flow condition are compared in Figure 7.

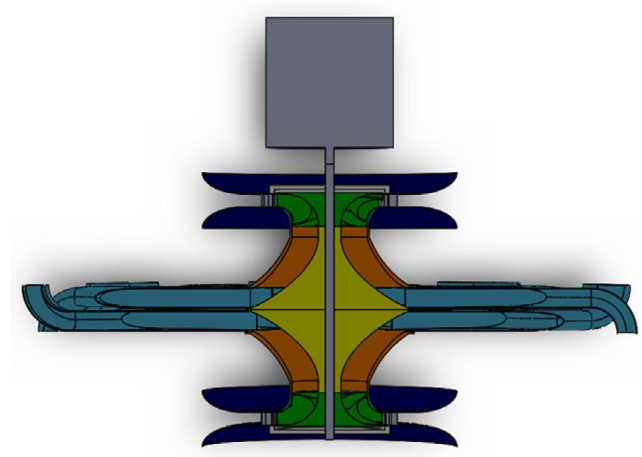

(a)

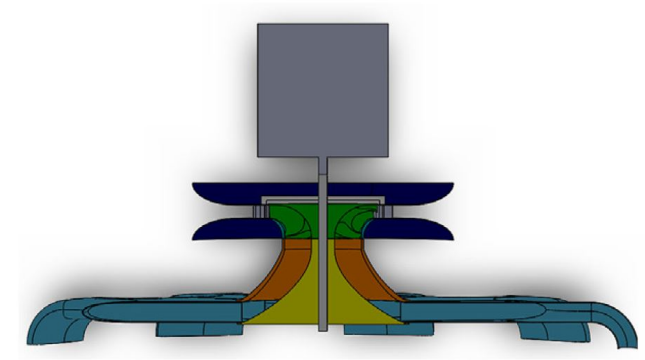

(b)

Figure 6. Schematics of the radial-inflow twin-rotor turbine modelled in the conventional OWC device and corresponding unidirectional radial-inflow turbine modelled in the Tupperwave device [5].

(a) Twin-rotor turbine. (b) Single rotor turbine.

In [15], the devices absorbed most power out of the waves for wave periods from 6 to $9 \mathrm{~s}$. They are therefore well adapted for the EMEC wave energy test site located off the coast of Scotland where such wave periods prevail. The scatter diagram of the EMEC wave climate is given in Figure 8.

For a fair comparison between the two devices, the turbines were optimised using the same methodology described below. The method described has no pretension of the being the best optimisation method. The turbine parameters to optimise are the diameter and the rotational speed. Their optimisation aims at maximising the device power output in the wave climate in which they are tested.

The optimisation of the turbines to maximise electrical power production in the EMEC wave climate was made in four steps:

1. Identification of the sea states for which the devices are the most productive over the year.

2. Assessment of optimal damping coefficients for the most productive sea states.

3. Assessment of turbine diameter and rotational speed to achieve optimal damping.

4. Verification that the damping achieved by the chosen turbine is close to optimal.

Basic turbine models were first used. A quadratic relationship was assumed between flow rate and pressure drop across the turbine such that:

$$
\Delta P_{t}=k_{t} q_{t}^{2}
$$

where $k_{t}$ is the damping coefficient of the turbine. The damping of the turbine is fundamental for the efficiency an OWC device in absorbing the wave energy. As a starting point, the turbine damping coefficients obtained by parametric optimisation in [13] carried out in regular waves were first tried over the whole EMEC wave climate and showed that the sea states of significant wave height $H_{s}=2-3 \mathrm{~m}$ and peak period $T_{p}=8-9 \mathrm{~s}$ are the most productive sea states over the year. Due to 
the large discrepancy of the sea states energy density, the most productive sea states are not the one that occur most often.

The turbine characteristics were then optimised for the most productive sea states. The damping coefficients maximising the devices' available power in the turbine $P_{\text {avail }}$ for those sea states were investigated in detail. Figures 9 and 10 show the evolution of the average pneumatic power flowing across the turbine $P_{\text {avail }}$ over the turbine damping coefficient in sea state $\left\{H_{s}=2 \mathrm{~m} ; T_{p}=8 \mathrm{~s}\right\}$ and $\left(H_{s}=3 \mathrm{~m} ; T_{p}=9 \mathrm{~s}\right)$ for the two devices, respectively.

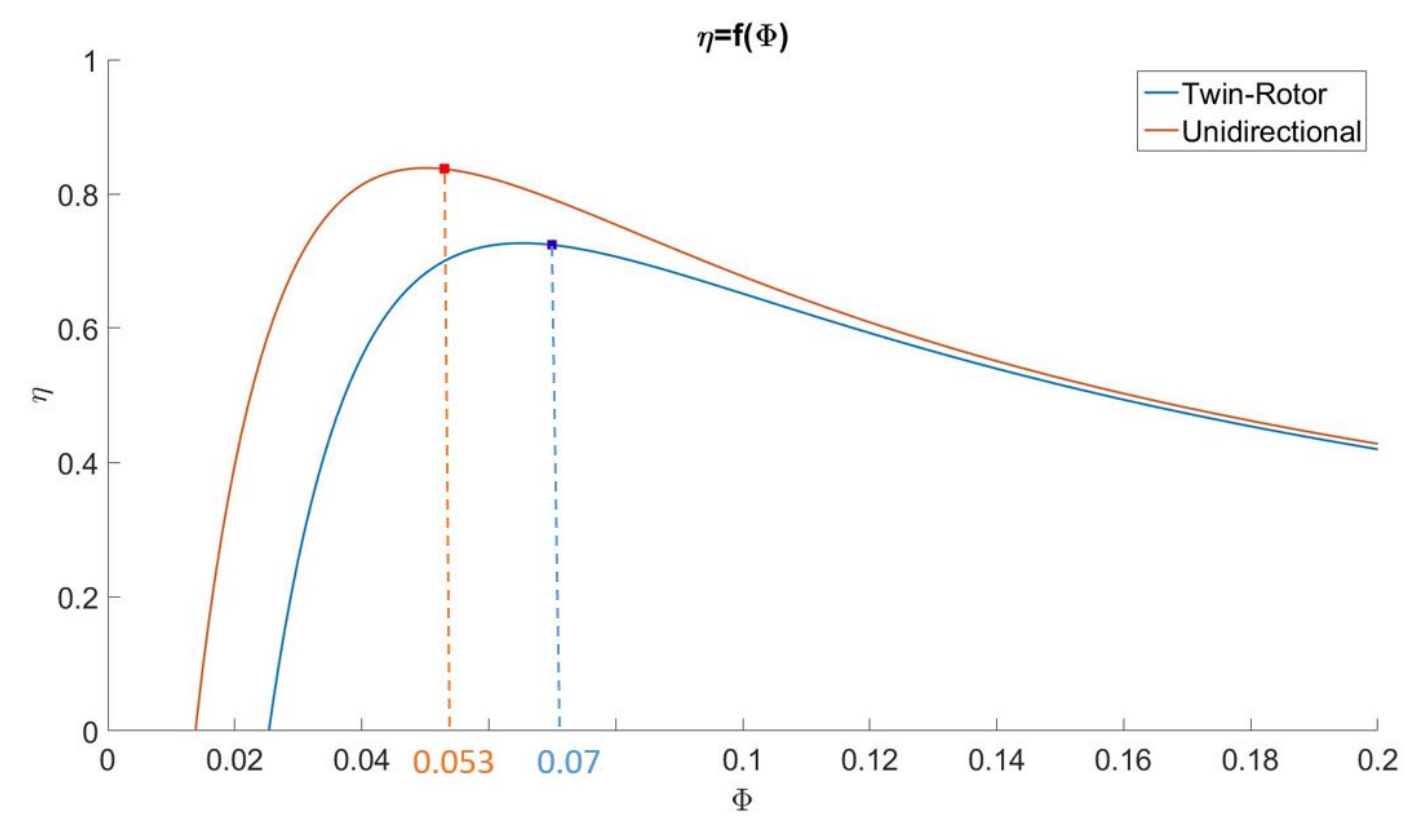

Figure 7. Total-to-static efficiencies for the twin-rotor and unidirectional turbines as functions of the flow coefficient.

It is observed that the ranges of damping coefficients maximising the power absorption from the waves are $k_{t}=35-75 \mathrm{~Pa} \cdot \mathrm{s}^{2} \cdot \mathrm{m}^{-6}$ for the conventional OWC and $k_{t}=1000-2500 \mathrm{~Pa} \cdot \mathrm{s}^{2} \cdot \mathrm{m}^{-6}$ for the Tupperwave device. The average flow rates achieved across the turbines in those conditions are denoted as $\overline{q_{t}}$.

It is fundamental that the turbines work close to their design flow coefficients $\Phi_{\text {opt }}$ (highlighted in Figure 7) which maximise their efficiencies. Therefore, for each turbine, a design rotational speed $\Omega_{d}$ is first chosen arbitrarily and its diameter is calculated from Equation (8) by:

$$
D=\sqrt[3]{\frac{\overline{q_{t}}}{\Omega_{d} \Phi_{o p t}}}
$$

The obtained turbine characteristics are given in Table 1.

Table 1. Chosen turbine characteristics.

\begin{tabular}{ccc}
\hline & Unidirectional & Twin-Rotor \\
\hline$\Phi_{\text {opt }}$ & 0.053 & 0.07 \\
$\Omega_{d}(\mathrm{rpm})$ & 4000 & 1000 \\
$\overline{q_{t}}\left(\mathrm{~m}^{3} \cdot \mathrm{s}^{-1}\right)$ & 2.8 & 9.8 \\
$\mathrm{D}(\mathrm{m})$ & 0.5 & 1.10 \\
\hline
\end{tabular}


It is then necessary to verify if the diameter and rotational speed selected induce a damping close to optimal for different turbine speeds. Figures 11 and 12 display the relationships between flow rates and pressure drops of the turbine models with the chosen parameters for different rotational speeds at which the turbines are likely to spin. They are compared with the simplified laws of optimised constant damping $k_{t}$. The damping achieved by the turbines for the different rotational speeds falls right in the range of optimum damping maximising wave absorption for sea states between $\left\{H_{s}=2 \mathrm{~m}\right.$; $\left.T_{p}=8 \mathrm{~s}\right\}$ and $\left(H_{s}=3 \mathrm{~m} ; T_{p}=9 \mathrm{~s}\right)$. This confirms that the diameters and rotational speeds of the turbine are well established. If it was not the case, the rotational speed of the turbines should be reconsidered until good agreement is obtained.

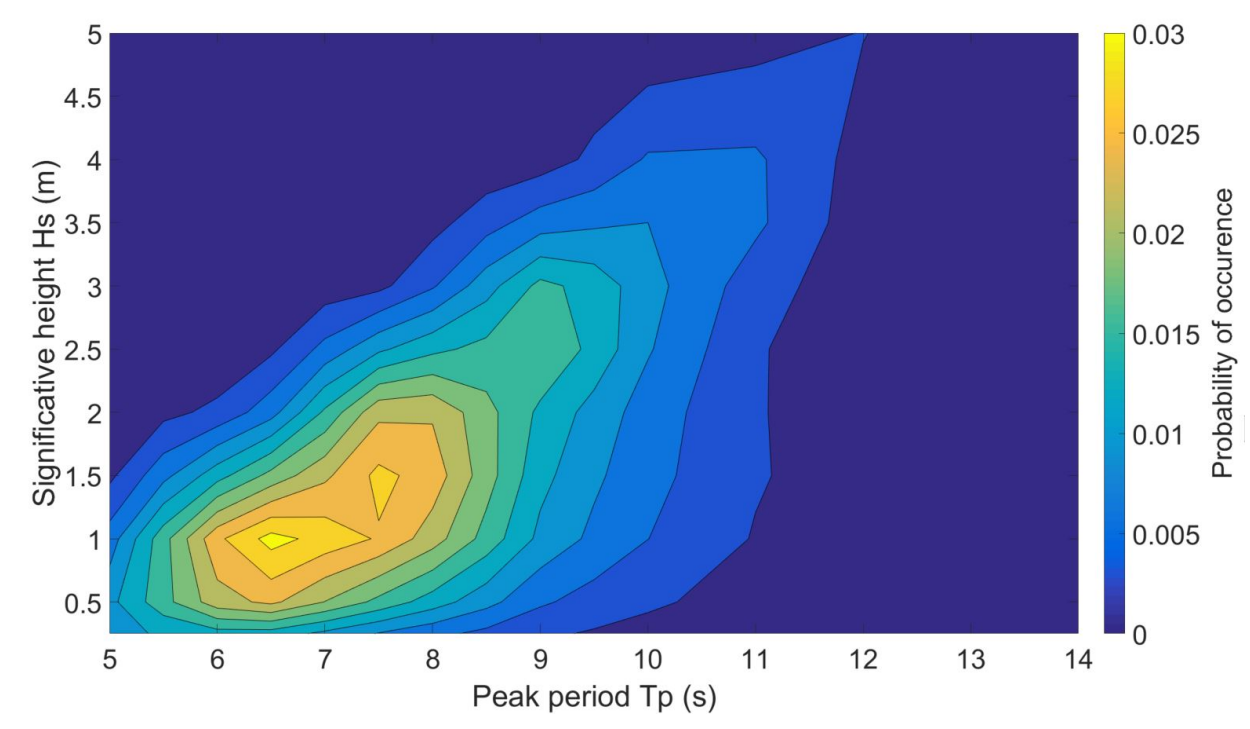

Figure 8. Scatter diagram of wave data statistic for the EMEC wave energy test site.

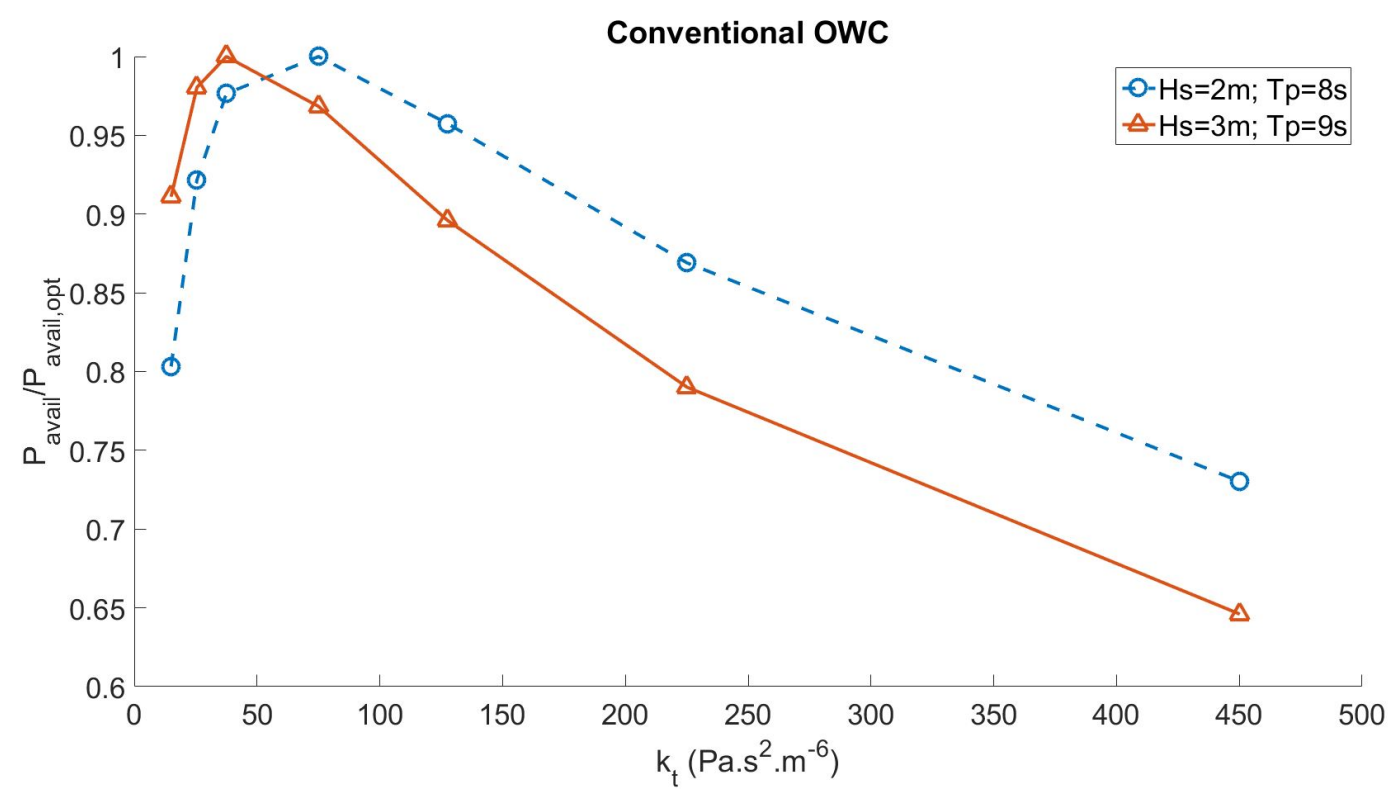

Figure 9. Evolution of pneumatic power available to the turbine with turbine damping coefficient for the conventional OWC.

It is observed in Figures 11 and 12 that the damping of the turbines increases slightly with the rotational speed. It is, however, interesting to note that, according to Figures 9 and 10, the optimal turbine damping becomes smaller for larger sea states where the turbine is likely to be spun faster. 
This shows that speed control of the turbines depending on the wave condition would theoretically enable the turbine damping to be matched with the optimal damping and hence maximise the absorbed power and the real delivered power production. In the case of the conventional OWC, the flow across the turbine very quickly varies and stops every $3-5 \mathrm{~s}$ to change direction. In this flow condition, a fixed-speed generator would experience severe shock loads on the generator shaft, whereas if the speed were allowed to increase, the inertia of the system would absorb some of the extra power input. This consideration led to the adoption of the more simple variable speed control law described in Section 2.5. With such a control law, the turbines gain to be designed so that their damping stays relatively constant with various rotational speeds.

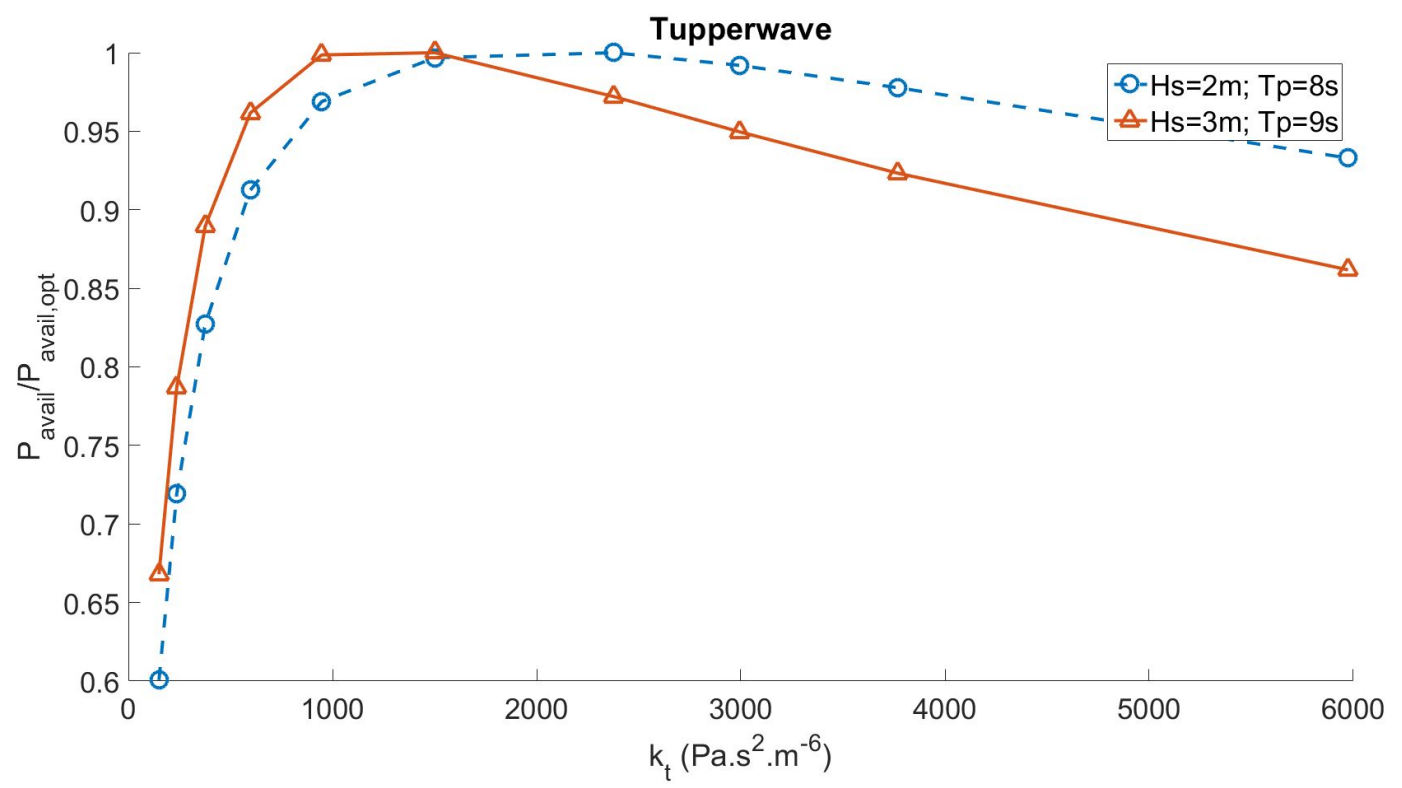

Figure 10. Evolution of pneumatic power available to the turbine with turbine damping coefficient for the Tupperwave device.

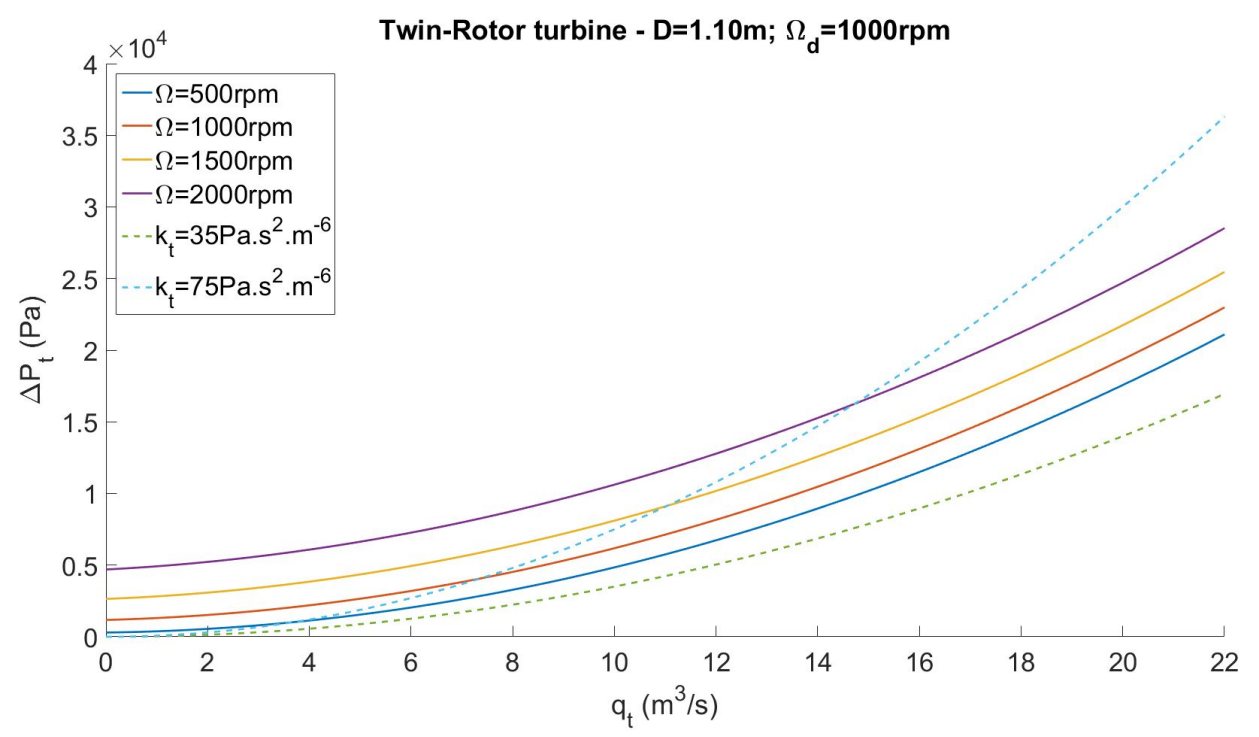

Figure 11. Relationship between pressure head $\Delta P_{t}$ and volumetric flow rate $q_{t}$ for the twin-rotor turbine at various rotational speeds $\Omega$ compared to the optimal fixed damping relationships.

The adaptation of the unidirectional turbine tested in [6] for the pneumatic damping needs of the Tupperwave turbine and the conventional OWC led to very different results on what concerns the size (diameter D) and the rotational speed. This is due to the different working conditions of 
the turbines in the two devices. The turbine in the Tupperwave device has a small diameter of $0.5 \mathrm{~m}$ but a very high design rotational speed of $4000 \mathrm{rpm}$. In addition of being less mechanically complex because of the absence of valve and of a single rotor, the chosen Tupperwave turbine is half the size of the conventional OWC turbine, it is therefore likely to be much cheaper. Unfortunately, a gearbox is necessary to bring down its high design speed to a commonly used generator design speed (1000 rpm) and the investment cost and maintenance issues associated with a gearbox are undesirable.

The Cordier diagram, see [28], is an empirical diagram commonly used as a tool by turbine designers. It indicates that if the optimum operating conditions are kept constant and if the design speed of the turbine is lowered, then the diameter of the turbine increases. This shows that the use of a gearbox could be avoided if a different turbine design with larger diameter was adopted. The Cordier diagram does not, however, provide any information on the blade shape (i.e., angles and blade width) and such designing exercise is out of the scope of the present research.

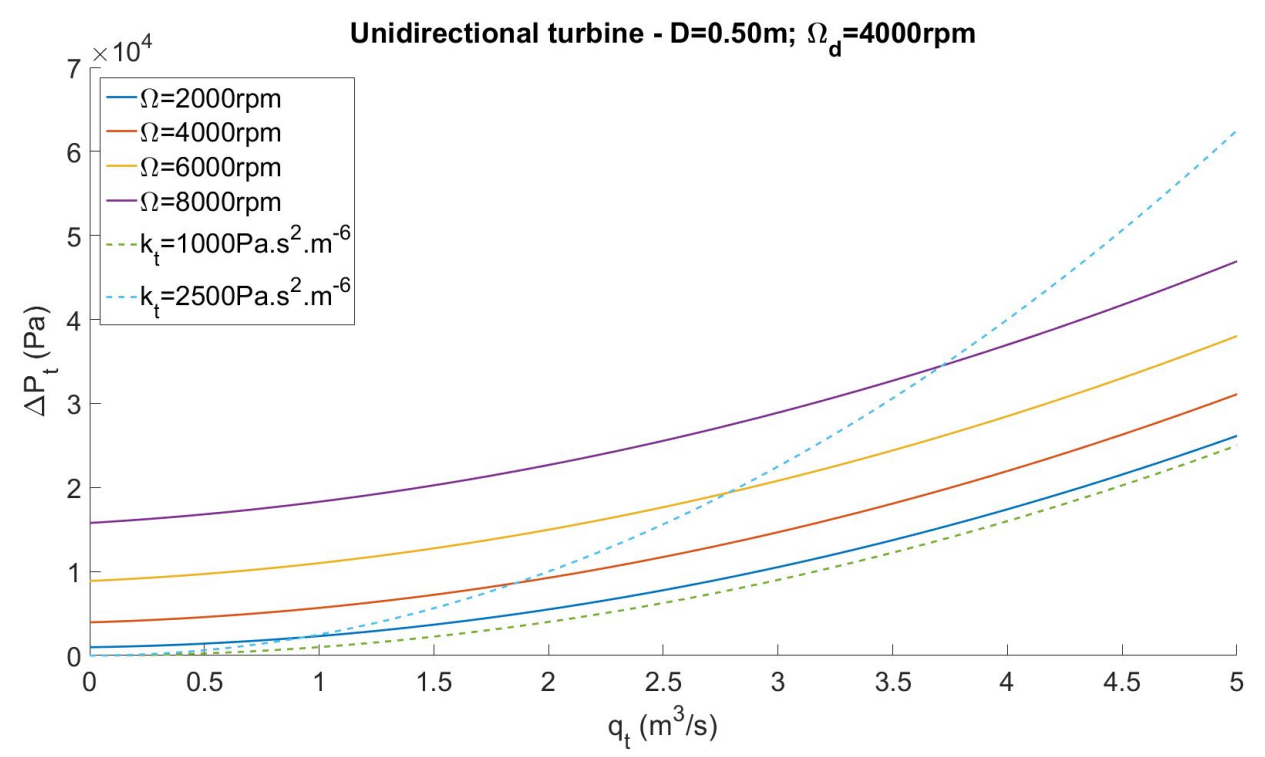

Figure 12. Relationship between pressure head $\Delta P_{t}$ and volumetric flow rate $q_{t}$ for the unidirectional turbine at various rotational speeds $\Omega$ compared to the optimal fixed damping relationships.

\subsection{Generator}

As described in Section 2.5, the efficiency of conventional electrical generators decays markedly for loads less than one-third of the rated power. During operation the electrical equipment, especially the power electronics, cannot be subjected to overloads. It is the purpose of the bypass valve to protect the electrical equipment from overloads. This security system should be used the least possible to reduce the risk of failure and increase the reliability of the device. For these reasons, the generator rated power needs to be carefully chosen. Similarly to the turbine, the generator should be sized according to the sea states of the site's wave climate for which the device extract the most wave power over the year. In those sea states, the generator should work at maximum efficiency but its rated power should be such that it is able to withstand the power peaks when high energy is available.

The most productive sea states of the EMEC wave climate for the devices studied in this paper are sea states of significant wave height $H_{s}=2-3 \mathrm{~m}$ and peak period $T_{p}=8-9 \mathrm{~s}$. According to Figure 5, the generator works at maximum efficiency for loads from $\Lambda=0.35$ onwards. The rated power of the generator is therefore chosen so that the average load of the generator in these sea states is close to 0.35 . It will be seen in Section 5 that the conventional OWC and the Tupperwave device produce similar amount of electrical power and a generator of $100 \mathrm{~kW}$ rated power was chosen for both devices. Its inertia was estimated from an exiting generator of similar rated power. 
Table 2 displays the optimised turbine and generator characteristics for the two devices studied. The turbines were assumed to be built in aluminium and their inertia were approximated based on their diameter.

Table 2. Turbine and generator parameters used in the wave-to-wire models.

\begin{tabular}{cccc}
\hline & & Tupperwave & Conventional OWC \\
\hline \multirow{2}{*}{ Turbine } & Type & Unidirectional radial inflow turbine & Self-rectifying radial inflow twin-rotor turbine \\
& Diameter $(\mathrm{m})$ & 0.50 & 1.10 \\
& Inertia $\left(\mathrm{kg} \cdot \mathrm{m}^{2}\right)$ & 1.7 & 38 \\
& Max. efficiency $(\%)$ & 86.6 & 73.9 \\
\hline Gearbox & Gearing Ratio & 4 & 100 \\
\hline Generator & Rated power $(\mathrm{kW})$ & 3.6 & \\
& Inertia $\left(\mathrm{kg} \cdot \mathrm{m}^{2}\right)$ & 1000 & \\
& Design speed $(\mathrm{rpm})$ & 2000 & \\
& Max. speed $(\mathrm{rpm})$ & 400 & \\
& Min. speed $(\mathrm{rpm})$ & &
\end{tabular}

\section{Numerical Model Validation}

The wave-to-wire models are validated in different power conversion steps. In [15], the models from wave to useful pneumatic power available to the turbine were validated. The turbine models added in this paper were established by the experimental tests carried out in [6] providing accurate modelling of the pneumatic to mechanical power conversion. The last power conversion step from mechanical to electrical power achieved by the generator is validated experimentally in this paper.

\subsection{Objective and Method}

The objective is to emulate the mechanical to electrical power conversion happening at full scale in the two devices studied and compare the results with the numerical models. This is achieved using Hardware-in-the-Loop (HIL) to simulate physically and in real time the turbine action on a real generator. The hardware is the rotary test rig of the Lir National Ocean Test Facilities (Lir-NOTF), MaREI Center, Ireland. The rig is basically composed of two $22 \mathrm{~kW}$ coupled electrical machines. One is used as a motor and acts as the prime mover (turbine). The other acts as the electrical generator and is connected to the local electrical grid using an off-the-shelf back-to-back converter. A picture of the rig is shown in Figure 13. Detailed descriptions of the rig, its capabilities and its limitations are described in $[29,30]$. The generator of the rotary test rig in the Lir NOTF includes several different configurations. For the HIL tests performed for validation, the selected generator configuration was the squirrel cage induction generator (SCIG) as suggested in [31].

The generator control law presented in Section 2.5 is directly applied on the real generator. This type of simulation is generally undertaken in the development of full scale devices. The controlled environment enables to simulate the equipment and control system in offshore-like conditions at a significantly lower cost prior to offshore tests.

The HIL system includes a Matlab-Simulink numerical model of the wave energy device from wave to mechanical power. The torque $T_{\text {turb }}$ created by the turbine on the shaft is solved based on the measured rotational speed of the rig. This torque is then applied in real time by the motor on the shaft. The connected generator converts the mechanical power into electrical power which is sent onto the grid. Since the numerical model depends on the turbine state, the measured rotational speed of the system is fed back into the numerical model at each time step.

The numerical model from wave to mechanical power is run at full scale while the hardware is run at model scale. The model scaling is determined by the hardware installation limits in power and speed. The scaling is executed through a two-step process. Since surface waves are gravity driven, the Froude similarity law of coefficient $\lambda$ is first used to scale down the turbine output power to fit on the rig installation which is limited to $22 \mathrm{~kW}$. For that, the Froude similarity law is applied on the turbine output 
torque $T_{\text {turb }}$ and on the turbine speed $\Omega$. As a result, the torque is reduced, but the speed is increased. To adapt the rotational speed of the model in line with the limitations of the rig ( $2200 \mathrm{rpm})$, the second step of the scaling process is the implementation of a virtual gearbox to the system with a virtual gearbox coefficient $G$, where a decrease in speed is exchanged for an increase in torque. The flow chart presenting the HIL system and the scaling method is displayed in Figure 14. As explained in Section 1, all parts of the device model (hydrodynamic, thermodynamic, turbine, generator) are strongly coupled and this is represented by the bidirectional arrows.

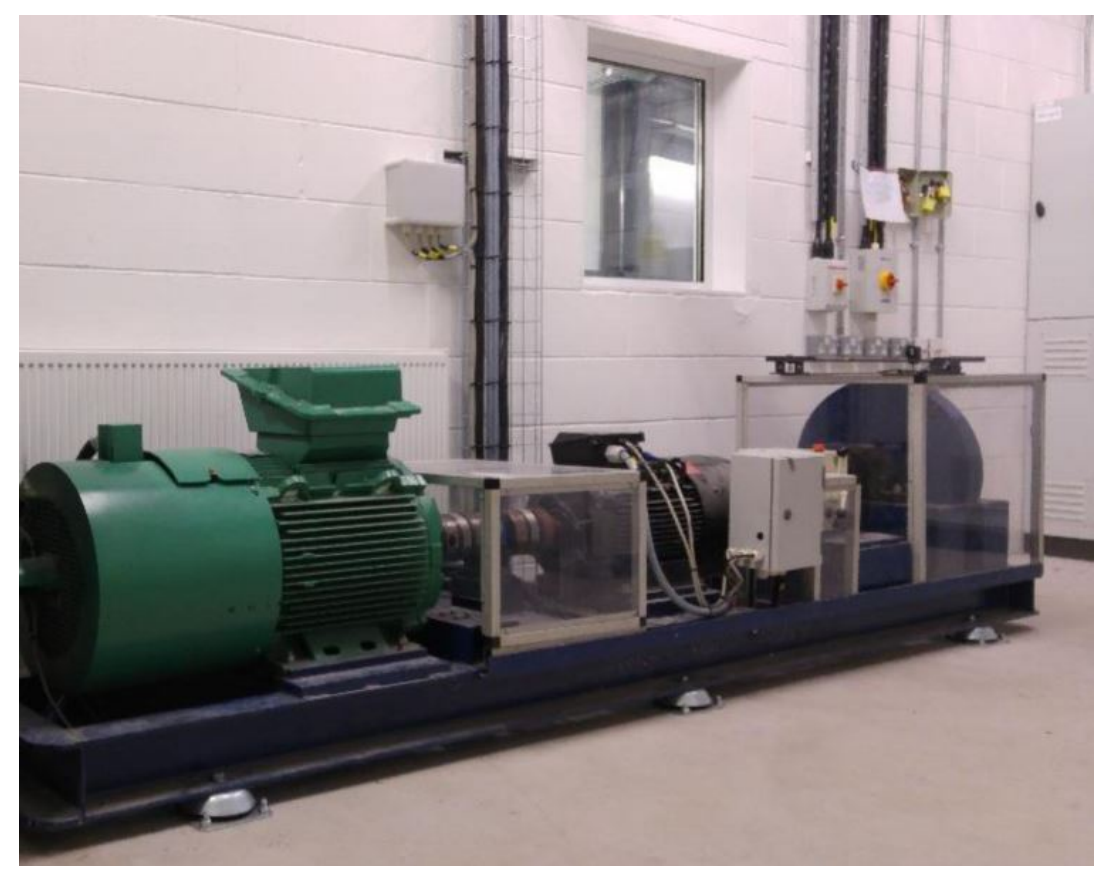

Figure 13. Rotary test rig of the Lir National Ocean Test Facilities (Lir-NOTF), used to emulate the turbine-generator systems of the devices.

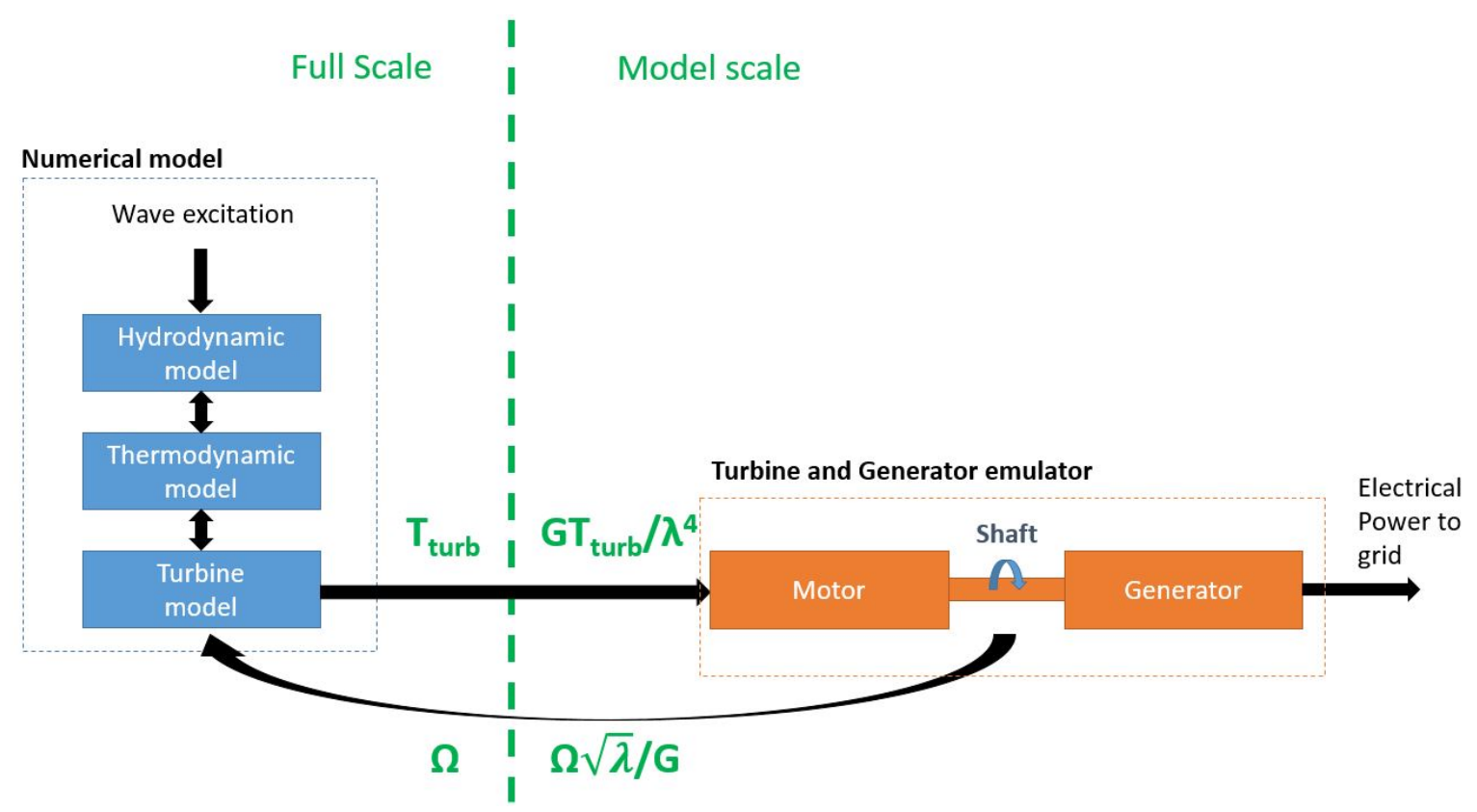

Figure 14. Hardware-in-the-Loop flow chart with scaling laws applied to the turbine speed $\Omega$ and output torque $T_{\text {turb }}$. 


\subsection{Hardware-in-the-Loop Results}

HIL tests were carried out for three common sea states of the EMEC wave climate and compared to the fully numerical results. The Pearson correlation coefficient for the electrical power $P_{e}$ and generator rotational speed $\Omega_{g e n}$ were calculated and are displayed in Table 3 . The coefficients are close to 1 and indicate good agreement between the fully numerical model and the tests with HIL.

Table 3. Pearson correlation coefficients between Hardware-in-the-Loop (HIL) and fully numerical results for the time series of electrical power $P_{e}$ and generator rotational speed $\Omega_{g e n}$ in three common sea states of the EMEC wave climate.

\begin{tabular}{ccccc}
\hline & \multicolumn{2}{c}{ Tupperwave } & \multicolumn{2}{c}{ Conventional OWC } \\
\hline & $\boldsymbol{P}_{\boldsymbol{e}}$ & $\boldsymbol{\Omega}_{\text {gen }}$ & $\boldsymbol{P}_{\boldsymbol{e}}$ & $\boldsymbol{\Omega}_{\text {gen }}$ \\
\hline$H_{S}=1.5 \mathrm{~m} ; T_{p}=7.5 \mathrm{~s}$ & 0.954 & 0.956 & 0.953 & 0.990 \\
$H_{S}=2 \mathrm{~m} ; T_{p}=8 \mathrm{~s}$ & 0.978 & 0.958 & 0.959 & 0.990 \\
$H_{s}=3 \mathrm{~m} ; T_{p}=9 \mathrm{~s}$ & 0.974 & 0.961 & 0.944 & 0.985 \\
\hline
\end{tabular}

For a more illustrative comparison, time series are displayed in Figures 15 and 16. The results in Table 3 and very good visual agreement are obtained; Figures 15 and 16 validated the last power conversion step of the fully numerical wave-to-wire models. It is noticeable for the conventional OWC that the high power peaks are reduced by the HIL due to limitations in the power output of the prime-mover motor of the rotary rig and the low power are increased by the HIL due to a baseline power output that the Regen drive needs for output to the grid. These effects are caused by intrinsic limitations of the rotary rig and are more noticeable for the conventional OWC than for the Tupperwave device because of the larger power fluctuations.

For the two devices, the generator control law gives satisfactory results since it allows the generator to spin close its design speed of $1000 \mathrm{rpm}$.

This validates the last power conversion stage and concludes the validation by experimental testing of the entire power conversion chain, as illustrated in Figure 2.
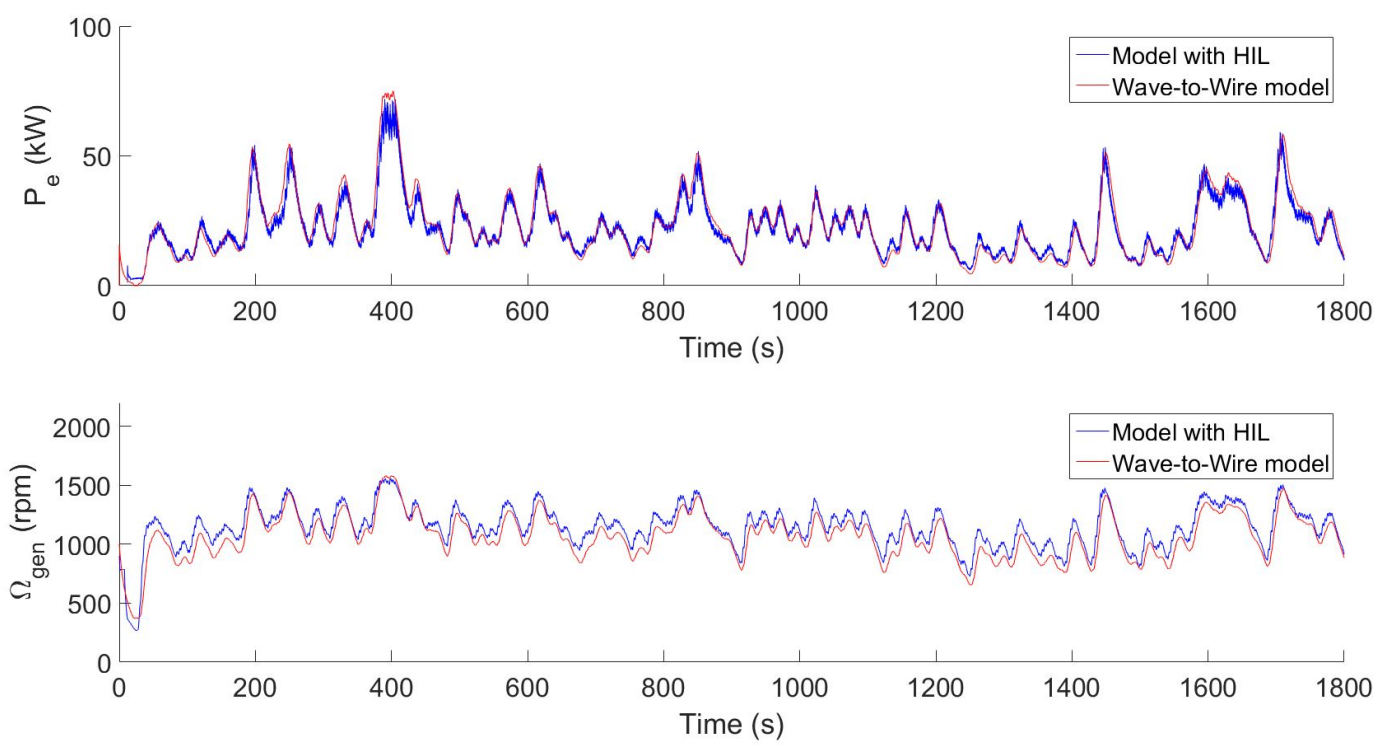

Figure 15. Time series of electrical power $P_{e}$ and generator rotational speed $\Omega_{g e n}$ obtained for the Tupperwave device with HIL and fully numerical model in sea state $\left\{H_{s}=2 \mathrm{~m} ; T_{p}=8 \mathrm{~s}\right\}$. 

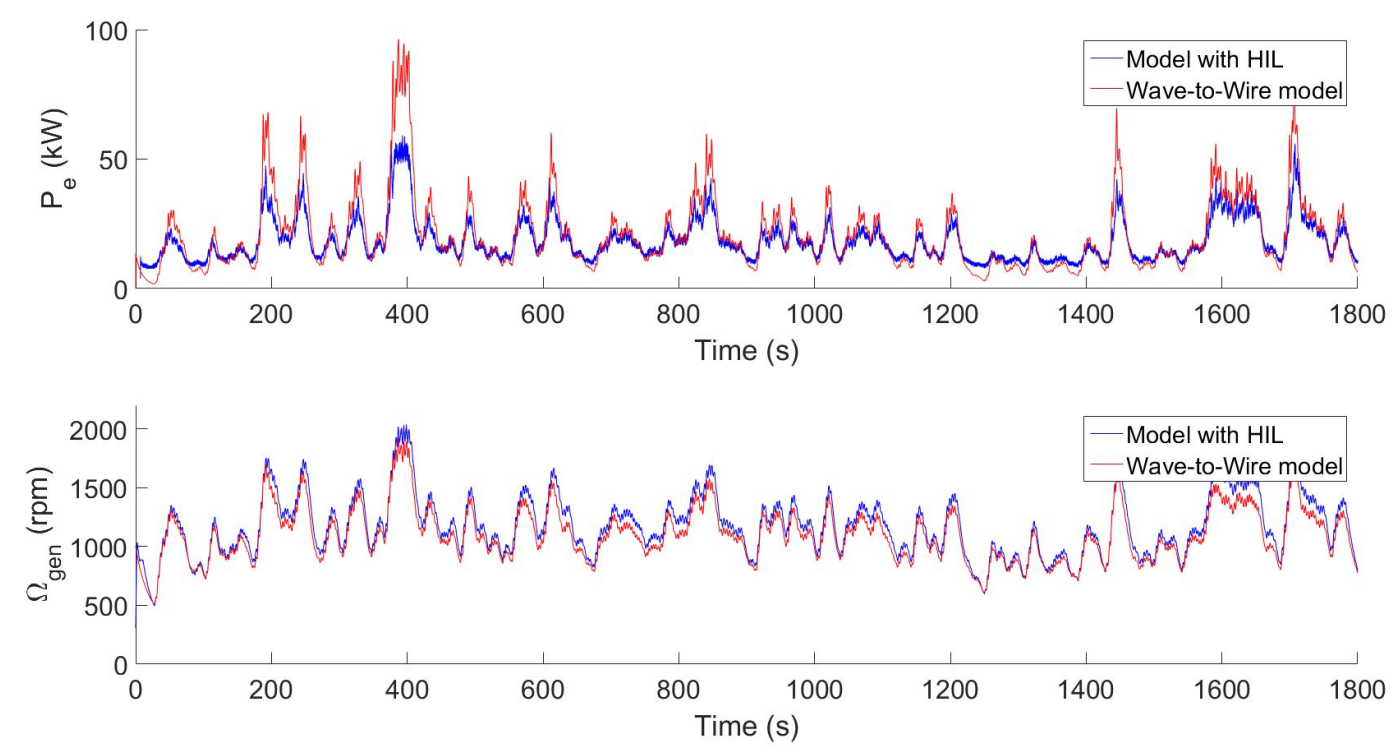

Figure 16. Time series of electrical power $P_{e}$ and generator rotational speed $\Omega_{g e n}$ obtained for the conventional OWC with HIL and fully numerical model in sea state $\left\{H_{s}=2 \mathrm{~m} ; T_{p}=8 \mathrm{~s}\right\}$.

\section{Wave-to-Wire Models Results}

Once, the Tupperwave and conventional OWC wave-to-wire models were validated against physical testing for all power conversion stages, their results are used to compare the device performances. The different power conversion processes are first compared for a single sea state. The devices' yearly performance in the EMEC test site are then compared both in terms of average electrical power output and power quality. Since both devices have the same floating structure, the same turbine aerodynamic geometry, the same generator and the same control law, this comparison aims at comparing the two devices' working principles.

The performances of the Tupperwave device are largely dependant on the non-return valves characteristics. Since the available literature provides no information on the achievable performances of non-return valves, three cases of valve characteristics were considered and detailed in Table 4 .

Table 4. Non-return valve characteristics considered in the Tupperwave device.

\begin{tabular}{ccc}
\hline Tupperwave Valves & $p_{\mathbf{0}}(\mathbf{P a})$ & $\alpha A_{v}\left(\mathbf{m}^{\mathbf{2}}\right)$ \\
\hline Case 1 & 1700 & 0.286 \\
Case 2 & 150 & 0.286 \\
Case 3 & 150 & 1.3 \\
\hline
\end{tabular}

The experience on non-return valves gained from the tank testing campaign of the Tupperwave device carried out in [15] is valuable. Even though their performances were poor, the characteristics of the valves used in [15] can be used as a starting point. In case 1 , the valves opening pressure $p_{0}$ and effective opening area $\alpha A_{v}$ corresponds to the ones obtained, at best, during the tank testing campaign. The values obtained at model scale were simply scaled up with Froude similarity law. In case 2, the opening area is kept unchanged and the opening pressure is set to $150 \mathrm{~Pa}$. This pressure applied on the area of the valve correspond to an opening force of $5 \mathrm{kgf}$ which seems reasonable for such a small valve. This case was used for the turbine-generator dimensioning described in Section 3. In the third case, the effective opening area of the valves is increased to $1.3 \mathrm{~m}^{2}$. We recall that the wall surface available between the OWC chamber and the HP (resp. LP) chamber is $10.6 \mathrm{~m}^{2}$. An effective opening area of $1.3 \mathrm{~m}^{2}$ therefore seems easily achievable. 


\subsection{Along the Power Conversion Chain}

It will be seen in Section 5.2 that both devices produce annually the most in the sea state $\left\{H_{s}=3 \mathrm{~m} ; T_{p}=9 \mathrm{~s}\right\}$. This sea state is considered in this section and the powers along the conversion chain are observed.

The amount of incident wave power reaching the devices is the same and only about $11 \%$ is effectively absorbed from the motion of the IWS in the devices. This absorbed power $P_{a b s}$ is the product of the volumetric flow rate $q_{I W S}$ displaced by the motion of the IWS (counted positive for upward motion) by the pressure in the OWC chamber and is the rate of work applied by the IWS on the air in the OWC chamber:

$$
P_{a b s}=p_{o w c} q_{I W S}=-p_{o w c} \dot{V}_{o w c}
$$

Figure 17 displays the absorbed power by the two devices. The power mainly flows from the IWS to the air in the chamber but it is alternatively positive and negative, meaning that energy is exchanged back and forth between the IWS and the air in the OWC chamber. At each stroke of IWS, a slight part of the power is stored by the air under the form internal energy. This power is then released back in the IWS at the next stroke in the opposite direction. This is caused by the spring-like air compressibility effect in the OWC chamber. This phenomenon is clearly described in [32]. Larger compressibility effect is observed in the OWC chamber of the Tupperwave device. The average power absorbed by the Tupperwave device is 5\% lower than the power absorbed by the conventional OWC.

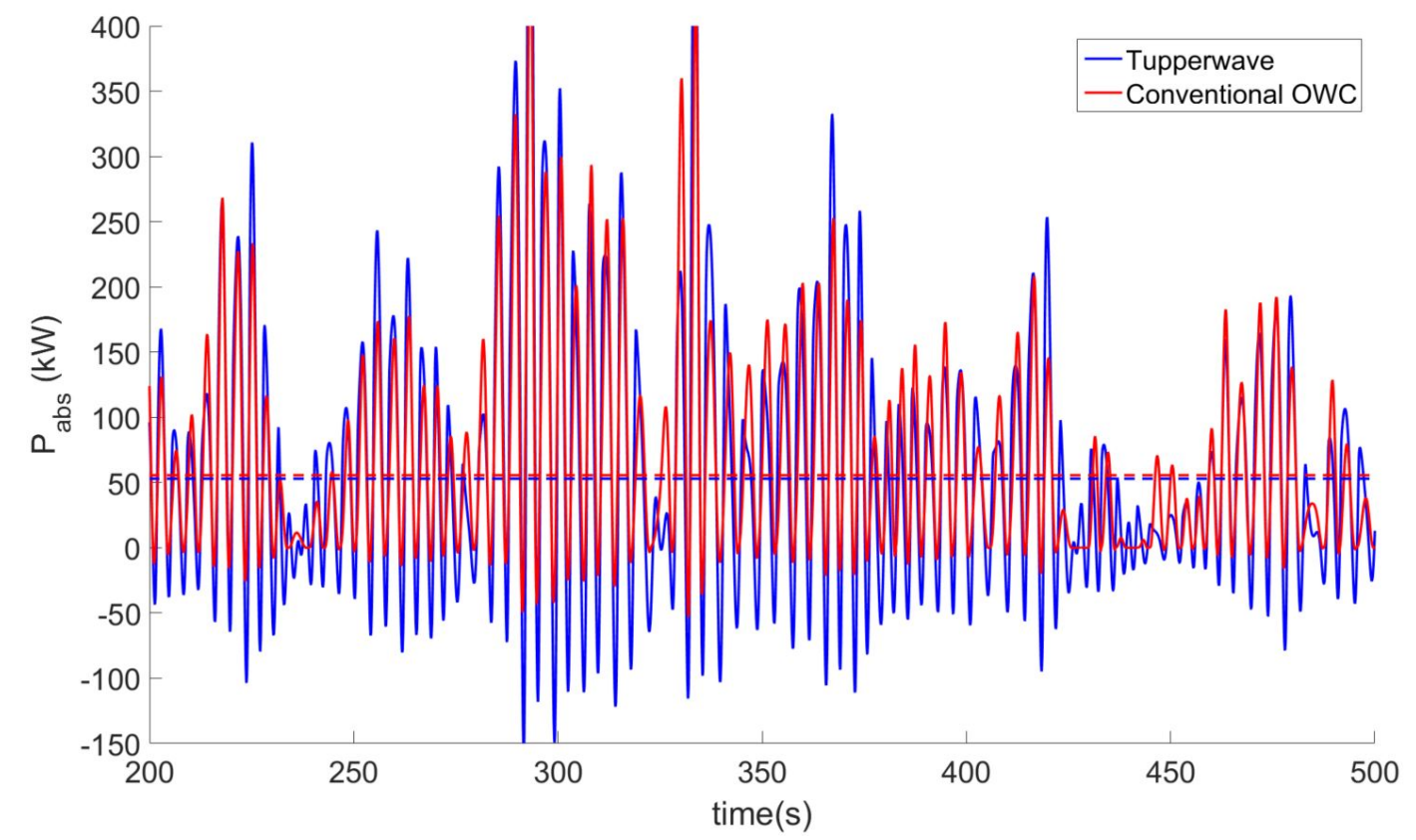

Figure 17. Power applied by the internal water surface (IWS) on the air in the OWC chamber (or absorbed wave power) in a conventional OWC and Tupperwave device (case 2) in sea state $\left(H_{s}=3 \mathrm{~m} ; T_{p}=9 \mathrm{~s}\right)$. Solid lines: Time series; dash lines: Average values.

The absorbed power is then converted into useful pneumatic power or power available at the turbine $P_{\text {avail }}$ which, in compressible flow, is the rate of enthalpy drop of the air across the turbine:

$$
P_{\text {avail }}=w_{t}\left(h_{\text {in }}-h_{\text {out }, \mathrm{s}}\right)
$$

where $h_{i n}$ is the specific enthalpy of the air at the entrance of the turbine, and $h_{o u t, s}$ is the specific enthalpy at the exit of the turbine for an isentropic expansion. Since the process is assumed adiabatic and isentropic without any dissipative losses, the absorbed power is, on average, entirely converted into power available at the turbine in the case of the conventional OWC: $\overline{P_{a v a i l}}=\overline{P_{a b s}}$. For the Tupperwave 
device, the air flow is rectified by the non-return valves to build a pressure differential between two accumulator chambers. This provides a smoothing of the pneumatic power across the turbine at the expense of pneumatic power losses across the valves. We define the valves efficiency as:

$$
\eta_{v}=\overline{\overline{P_{a v a i l}}}
$$

In the case presented in Figure 17, for the Tupperwave device, $80.5 \%$ of the absorbed power is actually converted into power available at the turbine and the rest is dissipated in the valves. The valves are thus $80.5 \%$ efficient. Figure 18 displays the resulting pneumatic powers available to the turbines in the Tupperwave device (case 2) and in the conventional OWC in sea state $H_{s}=3 \mathrm{~m}$ and $T_{p}=9 \mathrm{~s}$.

The power available at the turbines is then converted into mechanical power by the turbine. The smooth pneumatic power available at the turbine of the Tupperwave device is easier to harness and the turbine works very close to maximum efficiency while the turbine of the conventional OWC works on average $10 \%$ away from its maximum efficiency. Figure 19 illustrates this fact by showing the density of the working points along the turbines efficiency curves during the sea state. The unidirectional turbine of the Tupperwave device works $84 \%$ of the time within $1 \%$ of its maximum efficiency while the twin-rotor turbine only works in this state for $17 \%$ of the time.

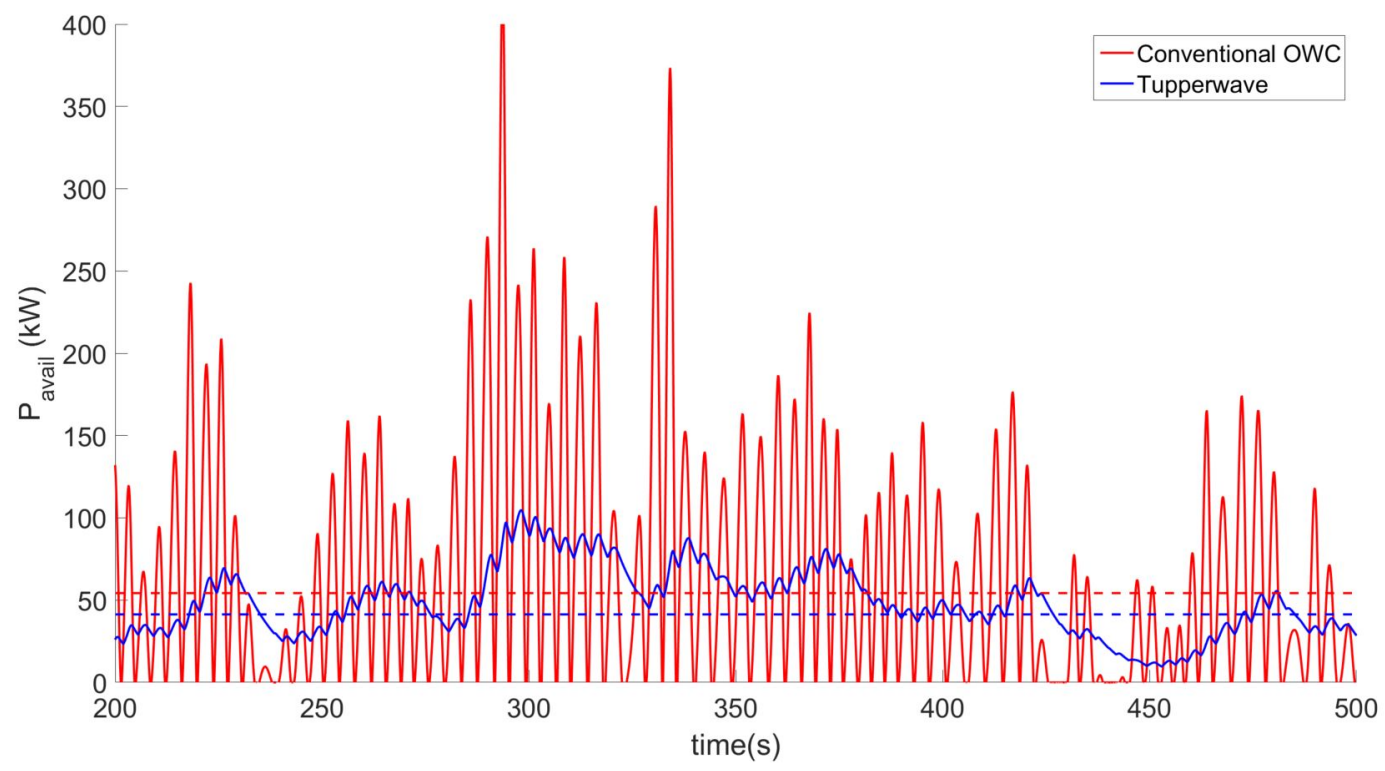

Figure 18. Pneumatic power available to the turbines in a conventional OWC and Tupperwave device (case 2$)$ in sea state $\left(H_{s}=3 \mathrm{~m} ; T_{p}=9 \mathrm{~s}\right)$. Solid lines: Time series; dash lines: Average values.

Finally the smoothed mechanical power available to the generator is converted into electrical power with an efficiency close to $94 \%$ for both devices. The time-series of the devices' electrical power production are displayed in Figure 20.

The significant electrical power fluctuations, delivered by wave energy converters in general, may have a negative impact on the power quality of the local grid to which the wave farms is connected [33]. They are an issue of concern for grid operators as they can introduce undesirable effects on the grid such as voltage and frequency variations and flickers [34]. Regarding Figure 20, the power fluctuations can be split in two groups: The wave-by-wave fluctuations or the wave-group by wave-group. Wave-by-wave power fluctuations cause the small peaks at every half wave-period visible for the conventional OWC and are due the high pneumatic power fluctuation between waves. These peaks are smoothed for the Tupperwave device. The Tupperwave accumulator system also smoothen the power between wave groups: Part of the energy of a wave group is stored under 
the form of pressure differential between the accumulators and is slowly released through the turbine until the next wave group. This also introduces a phase shift between the two curves. As a result the electrical power delivered by the Tupperwave device is smoother than for the conventional OWC. For the smoothing of the power, the conventional OWC relies only on the inertia of its turbine. The larger inertia of the twin-rotor turbine due to its larger diameter is an asset and the turbine is able to absorb temporarily the pneumatic power under the form of kinetic energy and alleviate the load variations on the generator. The inertia of the unidirectional turbine being smaller, the Tupperwave device relies almost only on the pneumatic power storing capacity to smoothen the turbine mechanical output power. The pneumatic power smoothing achieved by the Tupperwave device leads to smoother electrical power than the mechanical power smoothing achieved by the conventional OWC's turbine inertia.

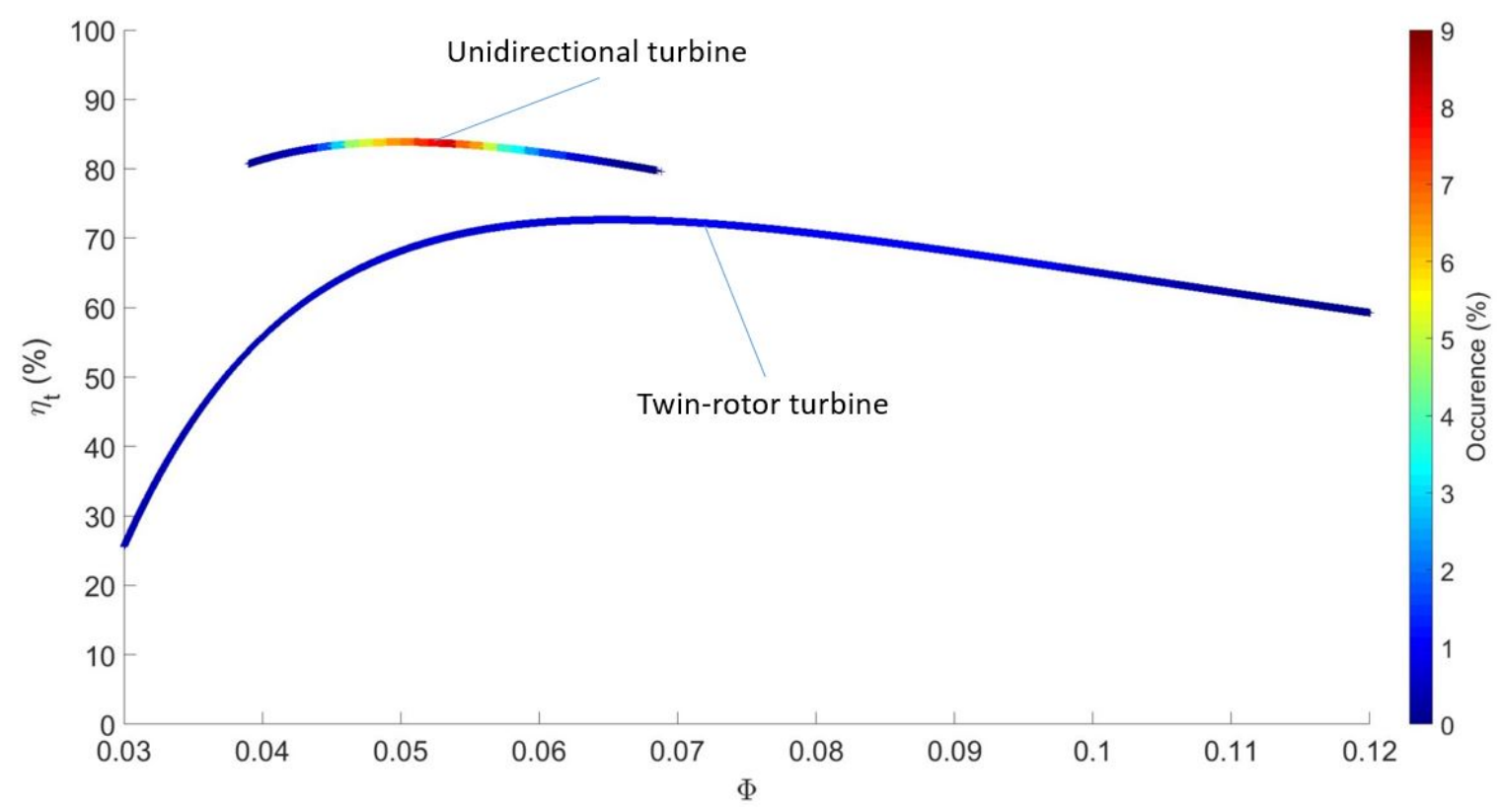

Figure 19. Percentage of occurrence of turbine working points in sea state $\left(H_{s}=3 \mathrm{~m} ; T_{p}=9 \mathrm{~s}\right)$.

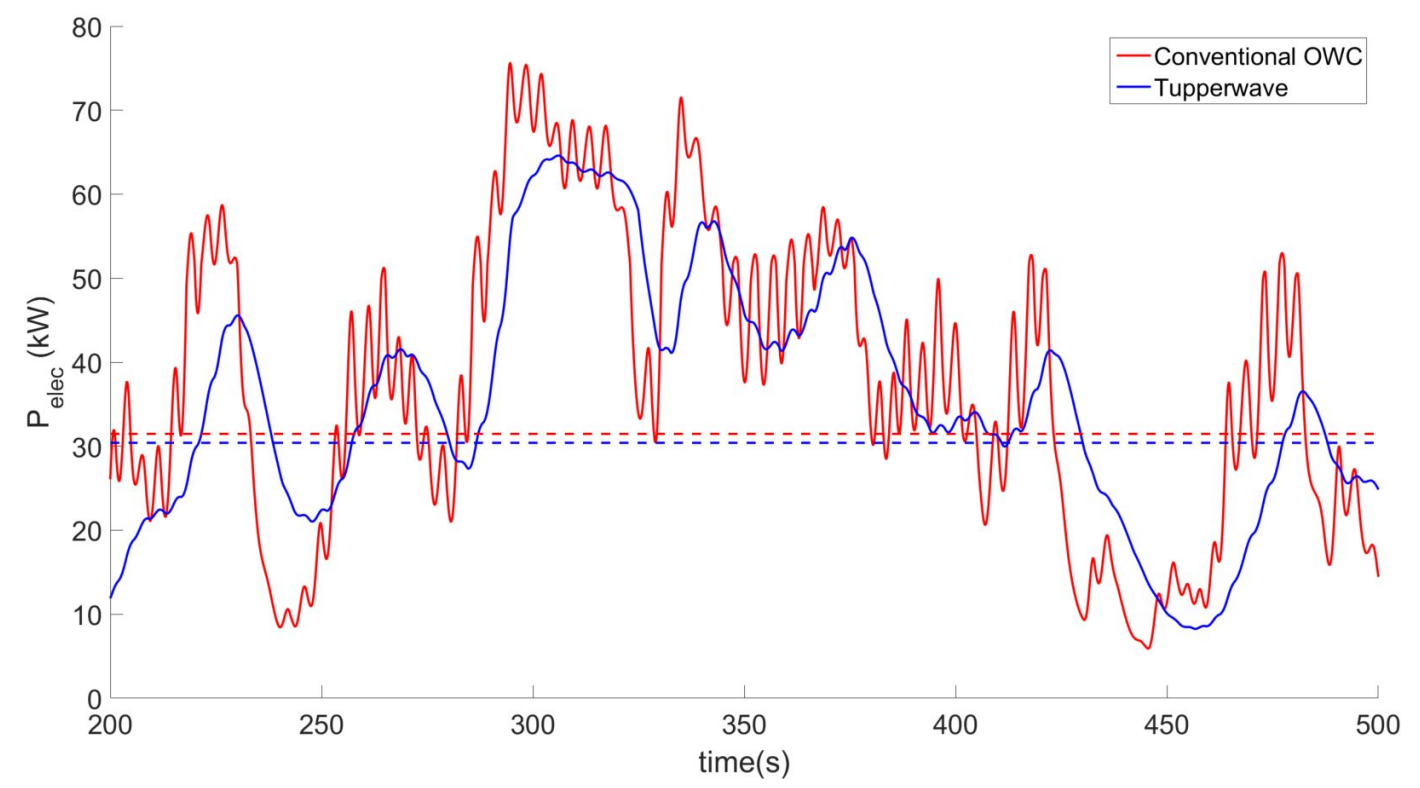

Figure 20. Electrical power produced by the conventional OWC and Tupperwave device (case 2) in sea state $\left(H_{s}=3 \mathrm{~m} ; T_{p}=9 \mathrm{~s}\right)$. Solid lines: Time series; dash lines: Average values. 
By adding a flywheel of inertia $150 \mathrm{~N} \cdot \mathrm{m}^{2}$ to the twin-rotor turbine, it is possible to obtain the same level of smoothness with the conventional OWC. Such inertia can be obtained with a $1.2 \mathrm{~m}$ diameter and $0.1 \mathrm{~m}$ thick iron wheel which weighs approximately $820 \mathrm{~kg}$. This naturally adds to the initial cost of the turbine and the added mass could lead to additional maintenance costs due to larger stresses on the bearings. It also causes a $3 \%$ reduction in power production.

A smaller flywheel of inertia $36.3 \mathrm{~N} \cdot \mathrm{m}^{2}$ can be added to the Tupperwave power-take off (PTO) system so that the resulting PTO inertia is the same as in the conventional OWC (see Table 2). This represents a $0.85 \mathrm{~m}$ diameter and $0.1 \mathrm{~m}$ thick iron wheel of about $400 \mathrm{~kg}$. The time-series of the devices' electrical power production are displayed in Figure 21. The pneumatic power smoothing of the accumulator chambers is combined with the mechanical power smoothing of the inertial PTO and the resulting electrical power is remarkably smooth. The addition of the flywheel only causes a $0.3 \%$ reduction in average electrical power production for this sea state.

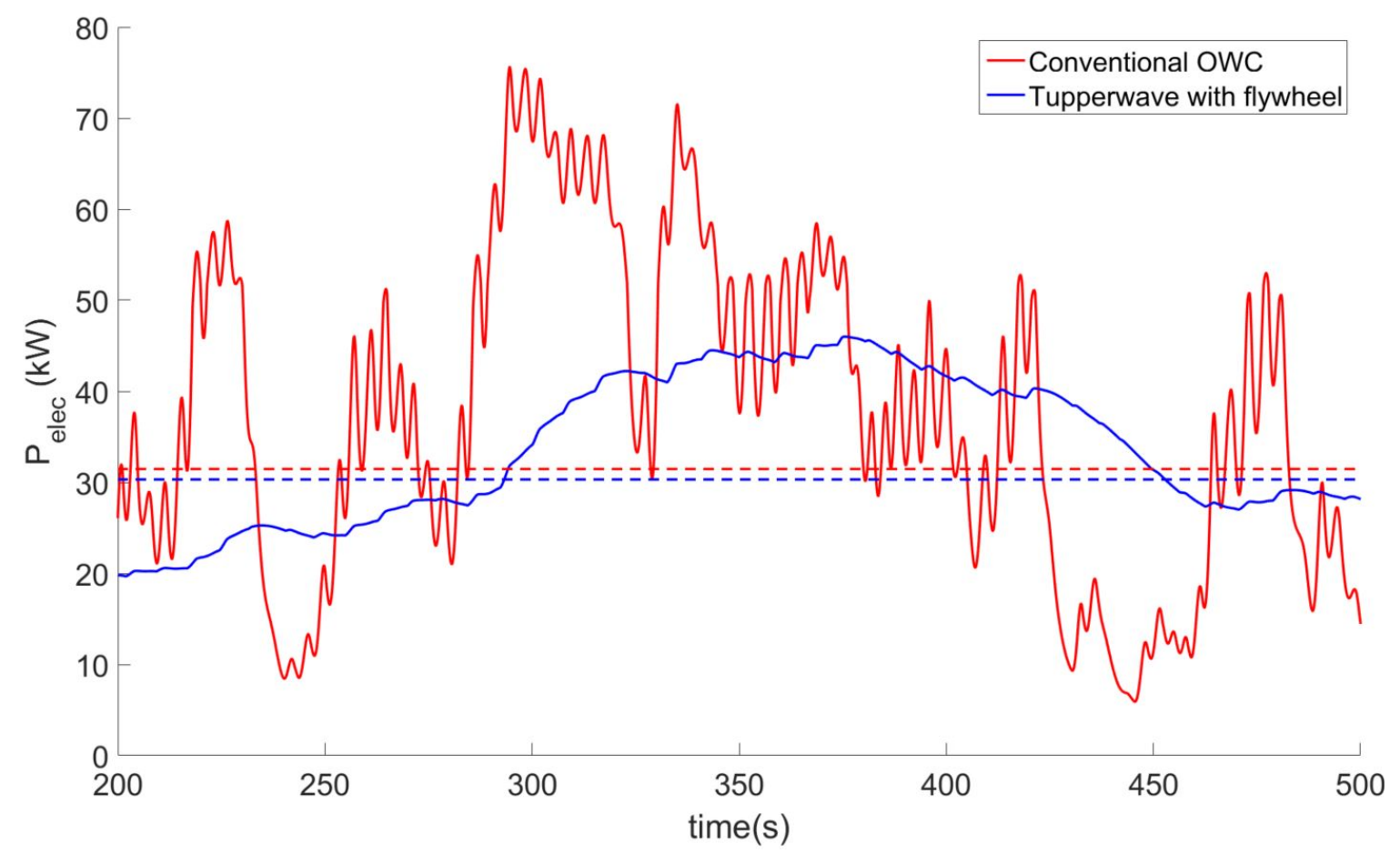

Figure 21. Electrical power produced by the conventional OWC and Tupperwave device (case 2) in sea state $\left(H_{s}=3 \mathrm{~m} ; T_{p}=9 \mathrm{~s}\right)$. A flywheel of inertia $36.3 \mathrm{~N} \cdot \mathrm{m}^{2}$ was added to the Tupperwave power-take off (PTO) so that the resulting PTO inertia is the same as in the conventional OWC. Solid lines: Time series; dash lines: Average values.

Finally, Figure 22 displays the average power available at the different stages of the power conversion chain and for the three Tupperwave valves cases displayed in Table 4. It is clear that the efficiency of the Tupperwave device depends on the efficiency of its non-return valves in the conversion from absorbed power to available power at the turbine. The valve efficiencies are of $63.7 \%, 77.9 \%$ and $96.9 \%$ for cases $1-3$, respectively. The Tupperwave device outperforms the conventional OWC in terms of electrical power production only if the non-return valves efficiency is greater than $80 \%$. Case 3 corresponds to the best possible case tested with valve efficiencies close to $100 \%$. In that case, the Tupperwave device produces $18 \%$ more electrical power than the conventional OWC. 


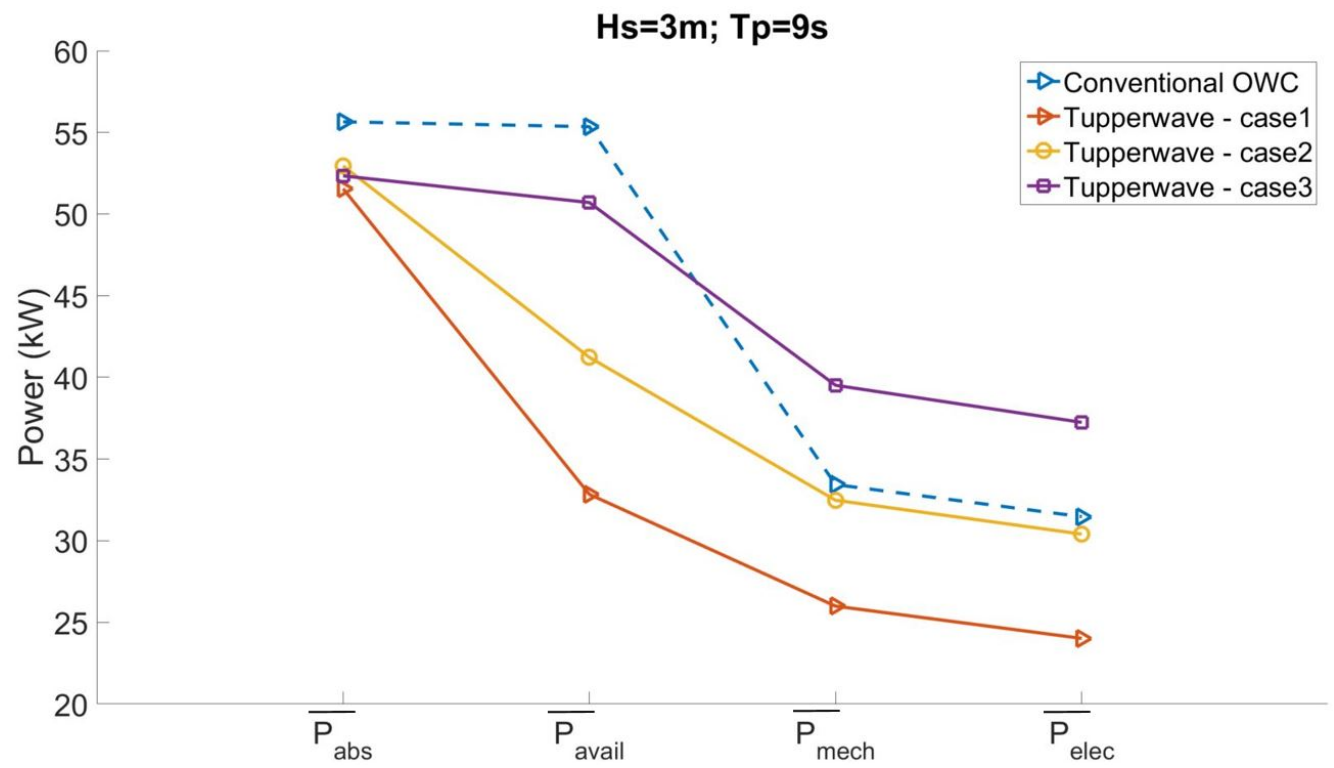

Figure 22. Average power along the power conversion chain of the conventional OWC and Tupperwave device in sea state $\left(H_{s}=3 \mathrm{~m} ; T_{p}=9 \mathrm{~s}\right)$.

\subsection{Yearly Power Performance Comparison}

A large number of simulations were run to assess and compare the device power performances on the EMEC wave energy test site in a one year time period. The comparison is based on several criteria listed below:

- Annual electrical power production.

- Electrical power fluctuation.

- Use of the security system (bypass valve).

The level of electrical power fluctuation $\mathrm{f}$ around its average value is calculated as the standard deviation normalised by the average value:

$$
f=\frac{1}{\bar{P}} \sqrt{\frac{1}{t_{f}} \int_{0}^{t_{f}}(P(t)-\bar{P})^{2} d t}
$$

Table 5 compares the devices' performances over a year in the EMEC test site. The performances of the Tupperwave device were assessed with the three different valve characteristics (see Table 4) and also when equipped with a flywheel providing the Tupperwave PTO the same inertia as the conventional OWC PTO.

Table 5. Devices performances over a year in the EMEC test site.

\begin{tabular}{lccccc}
\hline & & \multicolumn{2}{c}{ Tupperwave } & & Conventional OWC \\
\hline Valve characteristics & case 1 & case 2 & case 3 & case 2 & - \\
Flywheel inertia $\left(\mathrm{N} \cdot \mathrm{m}^{2}\right)$ & - & - & - & 36.3 & - \\
\hline Annual electrical production (MWh) & 70.6 & 97.6 & 119.5 & 99.3 & 99.9 \\
Average power fluctuation (\%) & 64.9 & 55.0 & 55.1 & 23.2 & 70.2 \\
Annual pneumatic energy dissipated in bypass valves (MWh) & 0.009 & 0.051 & 0.619 & 0.012 & 0.582 \\
Bypass valve opening per year & 44 & 287 & 3209 & 65 & 8537 \\
\hline
\end{tabular}


The results show that the Tupperwave device in case 2 produces very similar electrical power on all sea states to the conventional OWC. Figure 23 displays the amount of electrical energy produced by the Tupperwave device (case 2) in each sea state over a year. The results obtained for the conventional OWC being very similar, it is not represented here. As mentioned for the dimensioning of turbine-generator system in Section 3, the most producting sea states over the year are $H_{s}=2-3 \mathrm{~m}$ and $T_{p}=8-9 \mathrm{~s}$.

The values of average power fluctuations displayed in Table 5 are obtained for the most productive sea states. As illustrated in Figure 20, the result indicates that the electrical power delivered by the Tupperwave device is smoother than the conventional OWC in all cases. In addition to enabling the turbine to work close to maximum efficiency, the short term pneumatic power storage mechanism using air compressibility in the HP and LP chambers of the Tupperwave device contributes to the enhancement of power quality by mitigating the power fluctuations.

As a result of the smoother electrical power output, the Tupperwave device requires less use of the security system to protect its generator. At equal power production, the bypass valve opens 30 times less often over a year in in the Tupperwave device (case 2) than in the conventional OWC. This naturally leads to greater generator and power electronics longevity and reduces the risks of failure of the security system. Smoother operation of the turbine and generator also result in less fatigue and hence higher reliability of the system. Figure 24 shows on which sea states the use of the bypass valve is required by displaying the amount of pneumatic power dissipated in the bypass valve per year in each sea state for Tupperwave (case 2) and the conventional OWC. To reduce the use of the bypass valve by the conventional OWC, the generator rated power can be increased but this would reduce its efficiency in most sea states, see Figure 5. The total amount of pneumatic power dissipated through the bypass valve is, however, small compared to the yearly production.

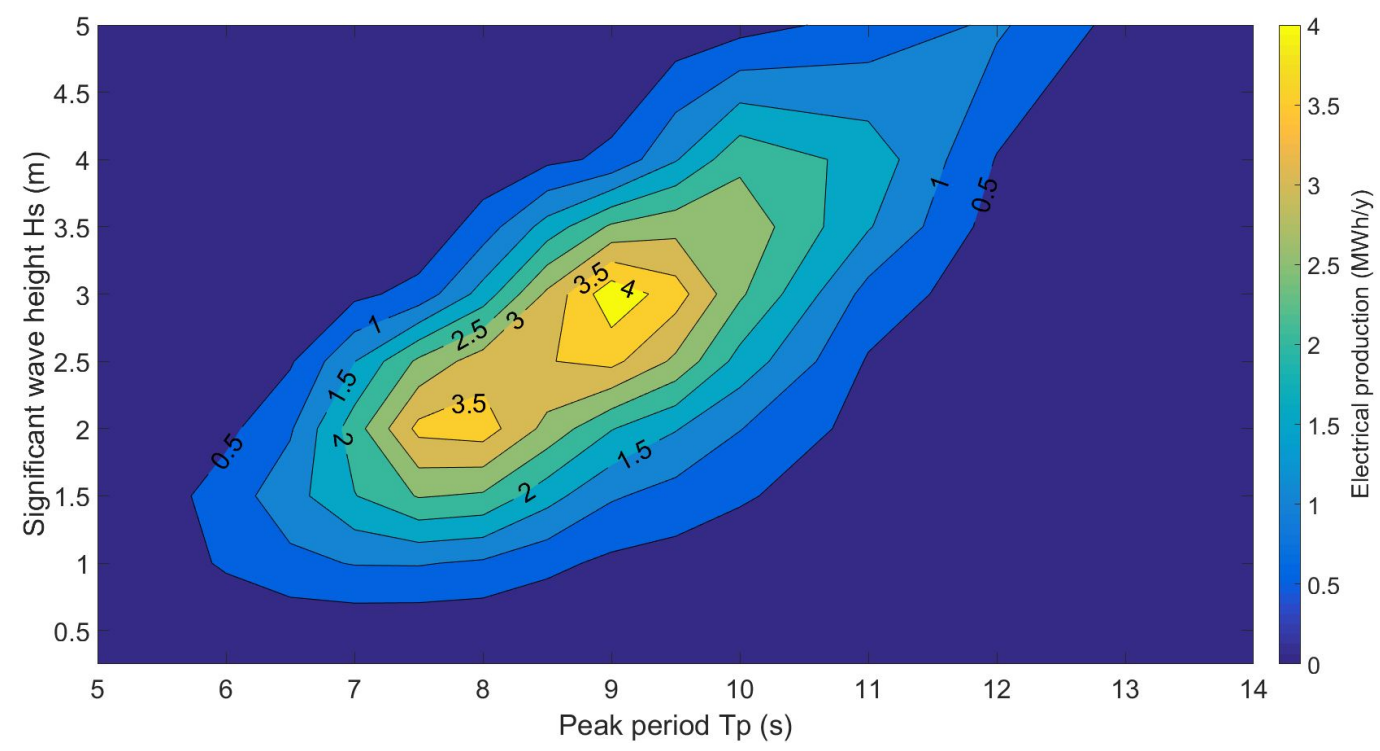

Figure 23. Electrical energy production on all sea states of the EMEC wave energy test site over a year by the Tupperwave (case 2). Quasi-identical figure is obtained for the conventional OWC device.

The addition of a flywheel to the Tupperwave PTO so that its inertia equals the inertia of the conventional OWC PTO (case 2 with flywheel) is very profitable in terms of electrical power quality: The average electrical power fluctuations are considerably reduced and thus, the use of the bypass valve is also reduced. A slight increase in annual electrical production is also observed. This increase is due to the larger production in low energy sea states $\left(H_{s}=1-2 \mathrm{~m}\right)$ where the device benefits from having a more inertial PTO. 


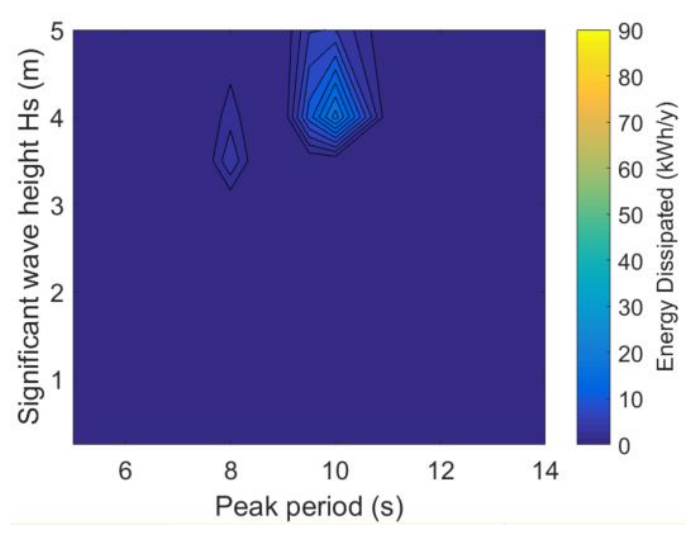

(a) Tupperwave: Case 2

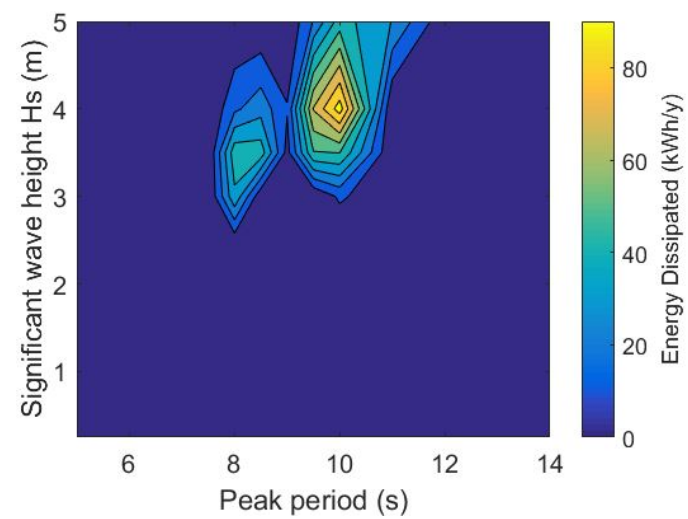

(b) Conventional OWC

Figure 24. Pneumatic power dissipated in the bypass valve in each sea state per year.

The results show that the Tupperwave device can compete with the conventional OWC provided that the non-return valves are correctly designed to be sufficiently efficient. Low opening pressure and large effective opening area are required. The physical feasibility and practicability of such non-return valves with adequate efficiency, however, remains to be proven.

\section{Conclusions}

In this research, the time-domain wave-to-wire models of the innovative Tupperwave device and corresponding conventional OWC were built. The two devices use the same floating spar buoy structure. The hydrodynamic equations are based on the linear wave theory and the thermodynamic processes are assumed isentropic. The two devices are equipped with the same floating structure geometry, turbine rotor geometry, generator and control law.

In a previous publication [15], the numerical models from wave to pneumatic power had been validated against tank testing experiments. In this paper, the conversion from pneumatic to electrical power was studied and validated against Hardware-in-the-Loop experiments, completing the validation of the entire power conversion chain. Their power performances in the EMEC wave energy test site were assessed using the validated wave-to-wire models after optimisation of their turbine-generator systems.

The methodology for dimensioning the turbine-generator systems to the wave climate of the test site was detailed and can be applied to similar design problems. The turbine used in the Tupperwave device is half the size of the turbine used in the conventional OWC and is also less mechanically complex. It is therefore likely to be cheaper. However, its high rotational speed requires the use of a mechanical gearbox which is associated with undesirable reliability and maintenance issues. The use of the gearbox could be avoided with a different turbine design.

The comparison of the device power performances allowed the assessment of the Tupperwave device concept against the conventional OWC. Due to its working principle, the Tupperwave device produces smooth pneumatic power across its turbine, allowing this latter to work close to maximum efficiency at all times. In the end, and despite its small PTO inertia, the Tupperwave device produces a smoother electrical power than the conventional OWC, enhancing power quality. This reduces the peak-to-average power ratio and hence requires less use of the security system that protects the generator from power peaks. The smoother operation is likely to have a positive impact on the system reliability. The power quality enhancement becomes particularly remarkable if the Tupperwave PTO inertia is increased to the same level as the conventional OWC PTO inertia. In terms of power production, if the non-return valves dissipate less than $20 \%$ of the absorbed wave power, the Tupperwave device can outperform the conventional OWC by up to $20 \%$. Such performance is achievable with sufficiently low opening pressure and a sufficiently large effective opening area of the valves. Further research on the Tupperwave concept should focus on the physical feasibility 
and reliability of such non-return valves in order to enable definitive conclusions on the relevance of the concept.

The use of the isentropic relationship between air density and pressure for the modelling of the Tupperwave device, in spite of the irreversible thermodynamic processes, represents a limit to the present study. A non-isentropic study of the Tupperwave device will be undertaken in future works to accurately model these processes.

Author Contributions: Conceptualization, P.B.; Data curation, P.B.; Formal analysis, P.B.; Funding acquisition, J.M.; Investigation, P.B. and J.K.; Methodology, P.B. and J.K.; Resources, J.M.; Supervision, J.M. and V.P.; Writing—original draft, P.B.; Writing—review and editing, P.B., J.K., V.P. and J.M.

Funding: The authors would like to acknowledge funding received through OCEANERA-NET European Network (OCN/00028).

Acknowledgments: The authors would like to thanks Bàrbara S. Lopes for kindly sharing the results of her experimental work on the twin-rotor turbine.

Conflicts of Interest: The authors declare no conflict of interest. The funders had no role in the design of the study; in the collection, analyses, or interpretation of data; in the writing of the manuscript, or in the decision to publish the results.

\section{Abbreviations}

The following abbreviations are used in this manuscript:

OWC Oscillating Water Column

HP High Pressure

LP Low Pressure

\section{References}

1. Czech, B.; Bauer, P. Wave energy converter concepts: Design challenges and classification. IEEE Ind. Electron. Mag. 2012, 6, 4-16. [CrossRef]

2. Falcão, A.F.O.; Henriques, J.C.C. Oscillating-water-column wave energy converters and air turbines: A review. Renew. Energy 2016, 85, 1391-1424. [CrossRef]

3. Falcão, A.F.O.; Henriques, J.C.C.; Gato, LMC. Self-rectifying air turbines for wave energy conversion: A comparative analysis. Renew. Sustain. Energy Rev. 2018, 91, 1231-1241.

4. Falcão, A.F.O.; Gato, L.; Nunes, E. A novel radial self-rectifying air turbine for use in wave energy converters. Part 2. Results from model testing. Renew. Energy 2013, 53, 159-164. [CrossRef]

5. Lopes, B.S.; Gato, L.M.; Falcão, A.F.O.; Henriques, J.C.C. Test results of a novel twin-rotor radial inflow self-rectifying air turbine for OWC wave energy converters. Energy 2019, 170, 869-879. [CrossRef]

6. Lopes, B. Construction and Testing of a Double Rotor Self-Rectifying Air Turbine Model for Wave Energy Recovery Systems. Language of Reference: Portuguese. Master's Thesis, Tecnico Lisboa, Lisbon, Portugal, 2017.

7. Borges, J.E. A Three-Dimensional Inverse Method for Turbomachinery: Part II—Experimental Verification. J. Turbomach. 1990, 112, 355-361. [CrossRef]

8. Masuda, Y.; McCormick, M.E. Experiences in pneumatic wave energy conversion in Japan. In Utilization of Ocean Waves-Wave to Energy Conversion; American Society of Civil Engineers: New York, NY, USA, 1986; pp. 1-33.

9. Kofoed, J.P.; Frigaard, P. Hydraulic Evaluation of the LEANCON Wave Energy Converter; DCE Technical Reports; Department of Civil Engineering, Aalborg University: Aalborg, Denmark, 2008.

10. Fleming, A.; MacFarlane, G.; Hunter, S.; Denniss, T. Power performance prediction for a vented oscillating water column wave energy converter with a unidirectional air turbine power take-off. In Proceedings of the 12th European Wave and Tidal Energy Conference. EWTEC, Cork, Ireland, 27 August-1 September 2017; p. 1204-1. 
11. Benreguig, P.; Murphy, J.; Sheng, W. Model scale testing of the Tupperwave device with comparison to a conventional OWC. In Proceedings of the ASME 2018 37th International Conference on Ocean, Offshore and Arctic Engineering OMAE2018, Madrid, Spain, 17-22 June 2018; American Society of Mechanical Engineers (ASME): New York, NY, USA, 2018.

12. Benreguig, P.; Vicente, M.; Dunne, A.; Murphy, J. Modelling approaches of a closed-circuit OWC wave energy converter. J. Mar. Sci. Eng. 2019, 7, 23. [CrossRef]

13. Vicente, M.; Benreguig, P.; Crowley, S.; Murphy, J. Tupperwave-preliminary numerical modelling of a floating OWC equipped with a unidirectional turbine. In Proceedings of the 12th European Wave and Tidal Energy Conference (EWTEC), Cork, Ireland, 27 August-1 September 2017.

14. Kelly, J.F.; Wright, W.M.; Sheng, W.; O'Sullivan, K. Implementation and verification of a wave-to-wire model of an oscillating water column with impulse turbine. IEEE Trans. Sustain. Energy 2016, 7, 546-553. [CrossRef]

15. Benreguig, P.; Pakrashi, V.; Murphy, J. Assessment of Primary Energy Conversion of a Closed-Circuit OWC Wave Energy Converter. Energies 2019, 12, 1962. [CrossRef]

16. Sheng, W.; Alcorn, R.; Lewis, A. Assessment of primary energy conversions of oscillating water columns. I. Hydrodynamic analysis. J. Renew. Sustain. Energy 2014, 6, 053113. [CrossRef]

17. Giorgi, G.; Ringwood, J.V. Consistency of viscous drag identification tests for wave energy applications. In Proceedings of the 12th European Wave and Tidal Energy Conference (EWTEC), Cork, Ireland, 27 August-1 September 2017.

18. Falcao, A.F.; Justino, P.A.P. OWC wave energy devices with air flow control. Ocean Eng. 1999, 26, $1275-1295$. [CrossRef]

19. Rajput, R. A Textbook of Engineering Thermodynamics; Firewall Media/Laxmi Publications (P) Ltd.: New Delhi, India, 2010.

20. Abdullah, M.A.; Yatim, A.H.M.; Tan, C.W.; Saidur, R. A review of maximum power point tracking algorithms for wind energy systems. Renew. Sustain. Energy Rev. 2012, 16, 3220-3227. [CrossRef]

21. Fä̈, F.X.; Henriques, J.C.; Kelly, J.; Mueller, M.; Abusara, M.; Sheng, W.; Marcos, M. Comparative assessment of control strategies for the biradial turbine in the Mutriku OWC plant. Renew. Energy 2019, 146, 2766-2784. [CrossRef]

22. Tedeschi, E.; Carraro, M.; Molinas, M.; Mattavelli, P. Effect of control strategies and power take-off efficiency on the power capture from sea waves. IEEE Trans. Energy Convers. 2011, 26, 1088-1098. [CrossRef]

23. Penalba, M.; Ringwood, J.V. A reduced wave-to-wire model for controller design and power assessment of wave energy converters. In Advances in Renewable Energies Offshore, Proceedings of the 3rd International Conference on Renewable Energies Offshore (RENEW 2018), Lisbon, Portugal, 8-10 October 2018; CRC Press: Boca Raton, FL, USA, 2018; p. 379.

24. Sheng, W.; Alcorn, R.; Lewis, A. A new method for radiation forces for floating platforms in waves. Ocean Eng. 2015, 105, 43-53. [CrossRef]

25. Duclos, G.; Clément, A.H.; Chatry, G. Absorption of outgoing waves in a numerical wave tank using a self-adaptive boundary condition. Int. J. Offshore Polar Eng. 2001, 11.

26. MATLAB, version 7.10.0 (R2010a); The MathWorks Inc.: Natick, MA, USA, 2010.

27. Falcão, A.F.O.; Gato, L.M.C.; Henriques, J.C.; Borges, J.E.; Pereiras, B.; Castro, F. A novel twin-rotor radial-inflow air turbine for oscillating water column wave energy converters. Energy 2015, 93, 2116-2125. [CrossRef]

28. Dick, E. Fundamentals of Turbomachines; Springer: Berlin/Heidelberg, Germany, 2015; Volume 109.

29. Rea, J.A.; Kelly, J.F.; Alcorn, R.; O'Sullivan, D. Development and operation of a power take off rig for ocean energy research and testing. In Proceedings of the Ninth European Wave and Tidal Energy Conference EWTEC 2011, Southampton, UK, 5-9 September 2011.

30. Kelly, J.F.; Christie, R. Applying Hardware-in-the-Loop capabilities to an ocean renewable energy device emulator. In Proceedings of the Twelfth IEEE International Conference on Ecological Vehicles and Renewable Energies (EVER), Monte Carlo, Monaco, 11-13 April 2017; pp. 1-7.

31. O'Sullivan, D.L.; Lewis, A.W. Generator selection and comparative performance in offshore oscillating water column ocean wave energy converters. IEEE Trans. Energy Convers. 2011, 26, 603-614. [CrossRef]

32. Falcão, A.F.; Henriques, J.C. The spring-like air compressibility effect in OWC wave energy converters: Hydro-, thermo- and aerodynamic analyses. In Proceedings of the ASME 2018 37th International Conference on Ocean, Offshore and Arctic Engineering, Madrid, Spain, 17-22 June 2018. 
33. Blavette, A.; O'Sullivan, D.L.; Lewis, A.W.; Egan, M.G. Impact of a wave farm on its local grid: Voltage limits, flicker level and power fluctuations. In Proceedings of the 2012 IEEE Oceans-Yeosu, Yeosu, Korea, 21-24 May 2012; pp. 1-9.

34. O'Sullivan, D.; Salcedo, F.; Blavette, A.; Santos, M.; Lewis, A. Case studies on the benefits of energy storage for power quality enhancement: Oscillating water column arrays. In Proceedings of the 4th International Conference on Ocean Energy (ICOE2012), Dublin, Ireland, 17-19 October 2012; Volume 1719.

(C) 2019 by the authors. Licensee MDPI, Basel, Switzerland. This article is an open access article distributed under the terms and conditions of the Creative Commons Attribution (CC BY) license (http:/ / creativecommons.org/licenses/by/4.0/). 